Pirineos, 155: 3 a 36, JACA; 2000

\title{
MORFOLOGÍA PERIGLACIAL DEL VOLCÁN LLULLAILLACO (CHILE/ARGENTINA) ${ }^{1}$
}

\author{
H. SCHRODER* \& M. MAKKI** \\ * Universitäl ErIangen-Niimberg, Instinut fir Geogmphie, Kodhstr. 4/4. \\ 91054 Erlangen, Alemania, e-mall hschroed $\$$ geographie unt-erlangen.de \\ * Universitït Erlongen-Niimberg, institut für Geologie, 5chlossgarten 5 , \\ 97054 Erlangen, Alemathia, e-mail: M.Makki@geologie.umi-eringende
}

SLMMARY.- The periglacint processes in the High Andes and residting perigincial pheroment ire presented here by example of Mt. Lhallailaco, at $24^{\circ} 43^{\circ} \mathrm{s}$ and $68^{\circ} 32^{\prime} \mathrm{W}$, on the frontier between Argentind and Chile. The iandforming processes reflect the recent and present extremely arid climate as ivell as the different age of the wolcatics. The range of perighatal Iandforms, the wertical distribution and assaciation that are described here, restule from the interations of climate and bedrocks. The upper perighainl limits are the highest of the woorld. The identified phenomena allow to differentiate between the sibondine (below $4,100 \mathrm{~m}$ ), subundine/andine $(4,100-4,300$ m), andine $(4,300-4,700 \mathrm{~m})$, lower perighcial $(4,700-5,800 \mathrm{~m})$, medium periglacial $(5,800-6,300 \mathrm{~m})$ and tipper periglacial $(6,300-6,739 \mathrm{~m})$ altitudinal zones. Due to the extreme aridity glaciers canmot form today. Their absence therefore is not due to insulficiently low temperatures, but to lack of humidity.

ZUSAMMENFASSLING.- Die periglazinle Oberfächentomung twit der sich daraus ergebende perightainle Formensthatz werden in Bereich der Hochamden am Beispiel des Lluilaillnco bei $24^{\circ} 43^{\prime}$ s.Br. whd $68^{\circ} 32^{\prime}$ tw. L. auf der Grenze zioischen Argentintien und Chite vorgestellt. Die Formugsprozesse spiegeln das subrezent und razent extrem trockene Klima sowie das wrierschiediche Alter der Vulkanite wider. Aus den neigungsdifferenzierten Wechselbeziehungen mit Klima tund Grstein ergeben sich eine Vielzahl won Periglazialformen, deren höhenwärtige Verteiltung und Vergesellschaftung beschrieben awerden. Die periglazinten Hohengronzen sind die höchsten unserer Erde. Entsprechend dem atssgegliederten Formenschatz kontute zwischen stibandiner (unter $4100 \mathrm{~m}$ ), subandiner/andine ( $4100-4300 \mathrm{~m}$ ), andiner $(4300-4700 \mathrm{~m})$, unterer periglazialer $(4700-5800 \mathrm{~m})$, mitherer periglazialer $(5800-6300 \mathrm{~m})$ und oberer periglazialer Sinfe $(6300-6739 \mathrm{~m})$ unterschieden

1 Traducción: Alexander Brenning, Erlangen, Se agradece la amable colaboración del geógrafo Marcelo Garrido, Pontificia Universidad Católiça de Chílę. 
werden. Die extreme Trockenheif fihtrt dazu, dass sich rezent keine Gletscher bulden können. Die fehlende Gletscherbildung ist also nicht Folge der Tempetaturverhattnisse, sondern der nicht ausreichenden Feuchtigketf.

RESUMEN.- A contintación se presentan los procesos perighiales y las forntas perighiates resultantes ent el piso alfo de la Cordillerd de los Andes, concretamente en el Volcoin Llultailaco a $24^{\circ} 43^{\prime} \mathrm{S}$ y $68^{\circ} 32^{\prime} \mathrm{W}$ en la zona fronteriza entre Chile y Argentina. Los procesos geomorfologicos refiejan el clima recierte y subreciente extremadomente arido asi como las diferentes edades de las volcanitas. Se describe la presencia de una gran anriedad de formas perigiaciales ysu distribucion altitudinal, diferenciando las que dependen del clima y de la roca. Los limites superiores del periglacial de la zona de estudio son los mis altos del planela. Segin los fenomenos periglaciales obseroudos, pueden diferenciarse los pisos altifudinales subandino (por debajo de los $4.100 \mathrm{~m}$ s.n.m.) subandino-dndino (4.100-4.300 m), andino (4.300-4.700 $\mathrm{m}$ ), periglacial inferior (4.700-5.800 $\mathrm{m}$ ), periglacial medio (5.800$6.300 \mathrm{~m}$ ) y periglacial superior $(6.300-6.739 \mathrm{~m})$. La aridez extrema imposibilita ta formación de un graciar en la actualidad. Por lo tanto, la ausencia de glaciares no se debe a temperaturas demasiado altas sino a la falla de humedad.

Keywords: Periglacial, landforming processes, extremely arid climate, rectilinear slope, frost patterned ground, Chile-Argentina.

\section{Introducción}

El trabajo de campo llevado a cabo en septiembre de 1995 y marzo/abril de 1996, permitió a los autores cartografiar las formas debidas a las heladas en la zona periglacial de mayor altitud y mayor insolación del planeta. Ésta se ubica en el Volcán Llullaillaco $\left(24^{\circ} 43^{\prime} \mathrm{S}, 68^{\circ} 32^{\prime} \mathrm{W}\right)$ fronterizo entre Chile y Argentina. Su cumbre de $6.739 \mathrm{~m}$ de altitud se encuentra en un área bajo condiciones climáticas excepcionales: Aquí coincide un intenso frío con aridez extrema, producto de la probablemente más alta insolación a nivel mundial. Como consecuencia, el Volcán Llullaillaco es el cerro más alto de la Tierra que no presenta un glaciar. Esto se debe a que entre $\operatorname{los} 24^{\circ}$ y $25^{\circ} \mathrm{S}$ la diagonal de máxima aridez de Atacama atraviesa el cordón principal andino. Este fenómeno ha sido descrito por un gran número de autores (LALER \& ERLENBACH, 1986; LAUER, 1988; GROSJEAN, MESSERLI \& SCHREIER, 1991; SCHROTT, 1994; RICHTER, 1995; RICHTER \& SCHRODER, 1998; SCHRÖDER, 1996; VUILLE, 1996, entre otros), a pesar de que no existen datos climáticos del piso alto del Llullaillaco, y sólo hay muy pocos datos climáticos de los alrededores. Toda el área de la cumbre muestra una aridez 
extrema que tan sólo permite la presencia de "campos de nevé" de poca extensión, pero no de glaciares.

\section{Objetivos de la investigación}

El Volcản Llullaillaco se encuentra en la parte más seca del cordón andino principal. En ningún lugar de altitud comparable en el planeta se observan precipitaciones tan bajas. Como consecuencia de que simultáneamente se alcanza una máxima de la oscilación térmica diaria (SCHMIDT, 1995), se constituye como el ambiente periglacial de mayor insolación y de mayor intensidad de la meteorización por insolación de nuestro planeta. El objetivo principal de lá investigación consistió en el inventario y cartografía, entre los 4.000 y $6.739 \mathrm{~m}$ de altitud, de la extensión espacial y la dinámica de este ambiente periglacial. Además se derivó de modo específico una zonificación altitudinal periglacial del área y una primera comparación e integración de los datos respecto de estudios sobre el desarrollo del modelado en las zonas de lluvias invernales (VEIT, 1998) y estivales (MERCER, 1985), a través de dataciones ${ }^{14} \mathrm{C}$ de sedimentos de terraza.

\section{El área de estudio}

El Volcán Llullaillaco es la elevación más imponente en el cordón principal andino del desierto de Atacama del norte de Chile. En el lado chileno, su cumbre se alza unos $3.800 \mathrm{~m}$ sobre el Salar de Punta Negra (Figura 1), su base local de erosión, que se encuentra a una distancia horizontal de solamente 36 $\mathrm{km}$. En los $24 \mathrm{~km}$ de distancia del Salar a los piedemontes del Llullaillaco, hay un desnivel de $1.000 \mathrm{~m}$. Los piedemontes presentan, en su parte más estrecha entre la Quebrada de las Zorritas y los afloramientos de lava, una diferencia de altitud de unos $1.000 \mathrm{~m}$ en una distancia horizontal de $9 \mathrm{~km}$ (Figura 2). Desde ahí, el cono volcánico propiamente tal se eleva unos $1.800 \mathrm{~m}$ en una distancia horizontal de $3 \mathrm{~km}$, y alcanza los $6.739 \mathrm{~m}$ de altitud (Figura 3).

En el lado argentino la estructura morfográfica es diferente. Allí, la base local de erosión, el Salar de Llullaillaco, se encuentra a $3.750 \mathrm{~m}$ de altitud y a una distancia de $20 \mathrm{~km}$ (Figura 1). Desde ahi, los piedemontes suben más de $1.200 \mathrm{~m}$ en unos $17 \mathrm{~km}$ de distancia hasta la lava del Llullaillaco. Igual que en el lado chileno, el cono volcánico se eleva más de $1.800 \mathrm{~m}$ en una distancia de unos $3 \mathrm{~km}$. El área de levantamiento cartográfico comprende altitudes entre los 4.000 y $6.739 \mathrm{~m}$ en el cono volcánico y su entorno. 
PIRINEOS 155

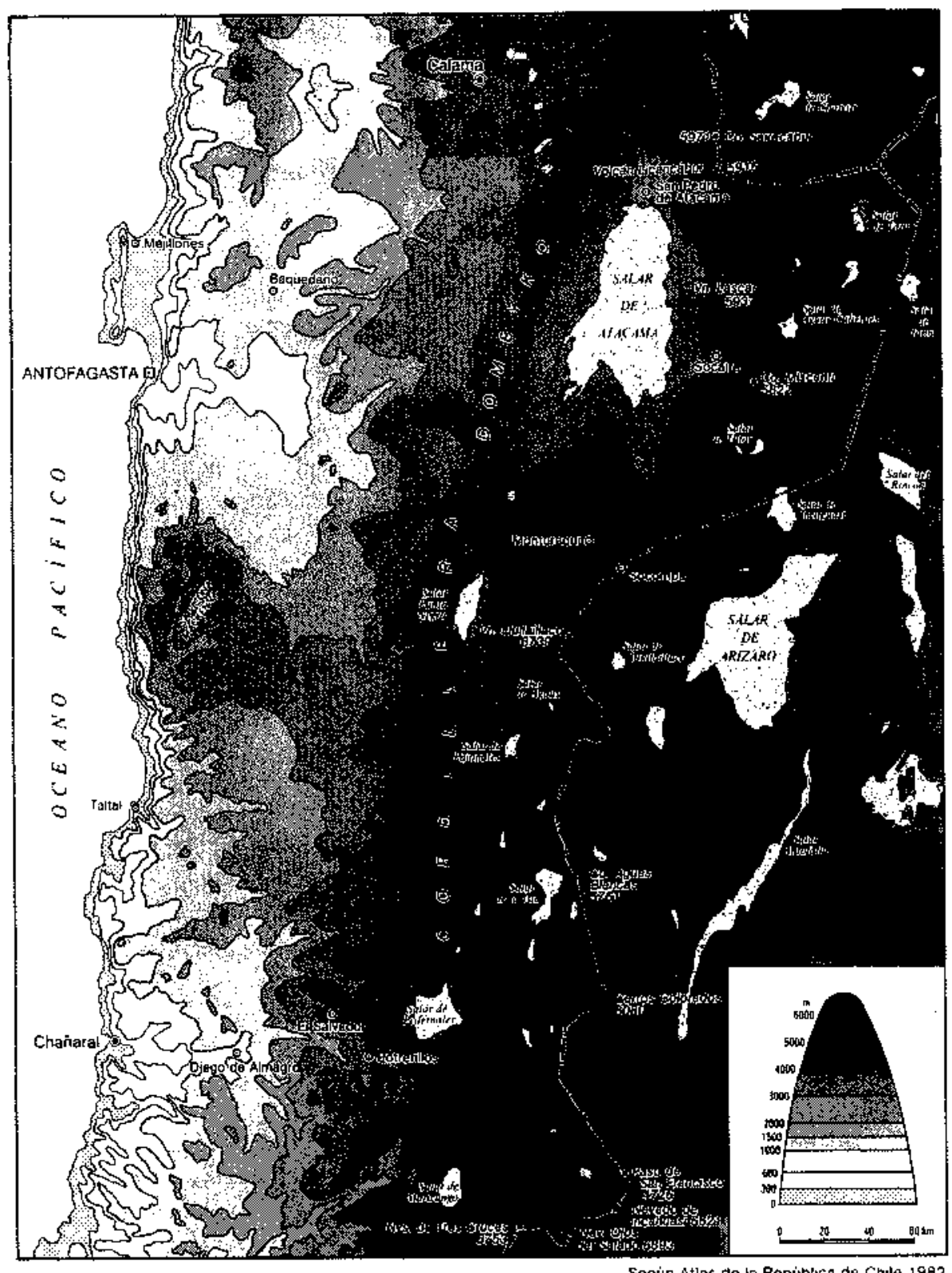

Figura 1. El Norte Grande de Chile entre Copiap 6

y Calama (según Atlas de la República de Chile 1982).

Figure 1. The Big Norih of Chite between Copiapo and Calama.

6 


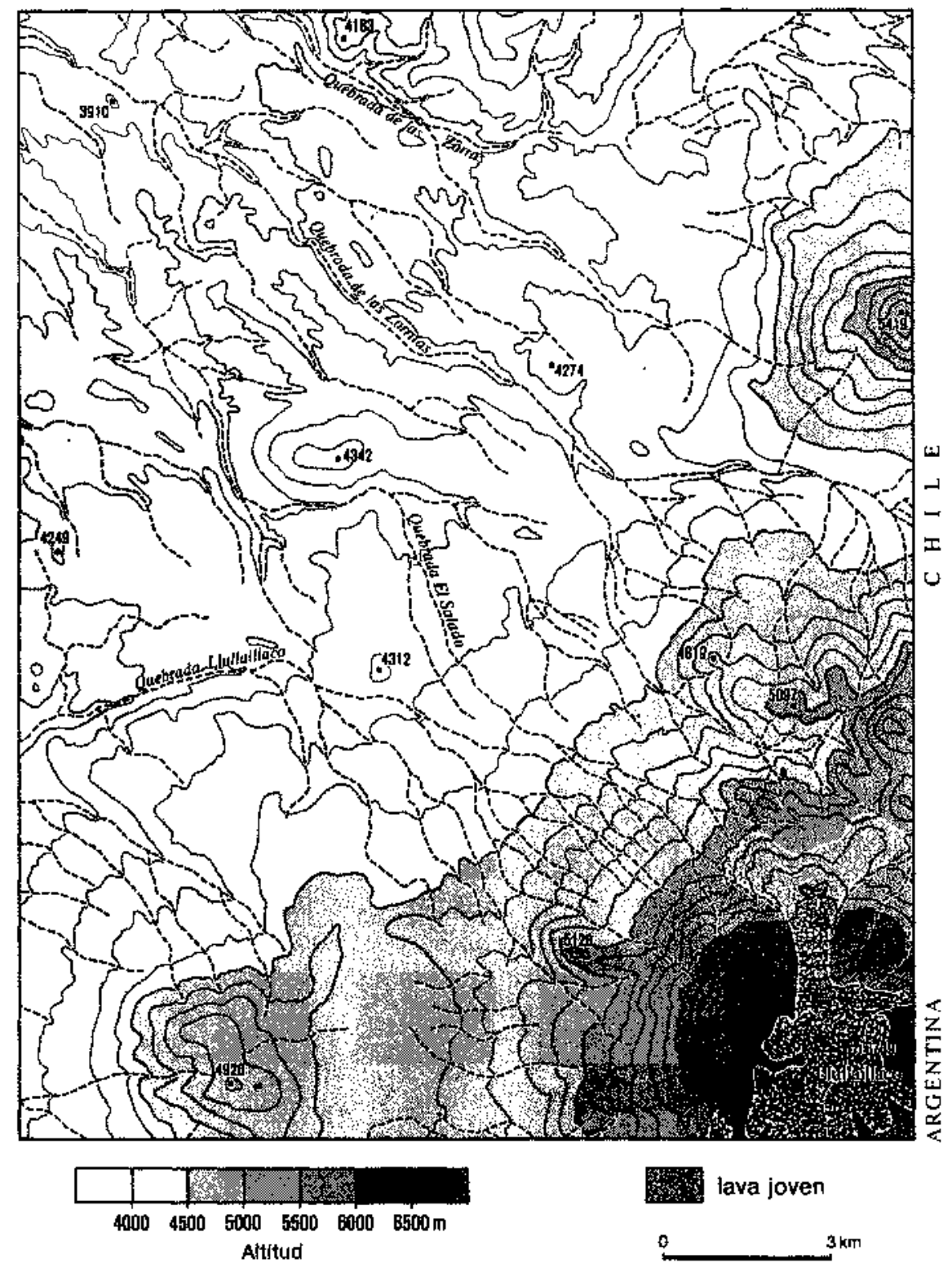

Figura 2. Las altitudes en la vertiente noroccidental del Llullaillaco. Figure 2. Altitude conditions on the north-westem slope of Me. Lluliaillaco. 


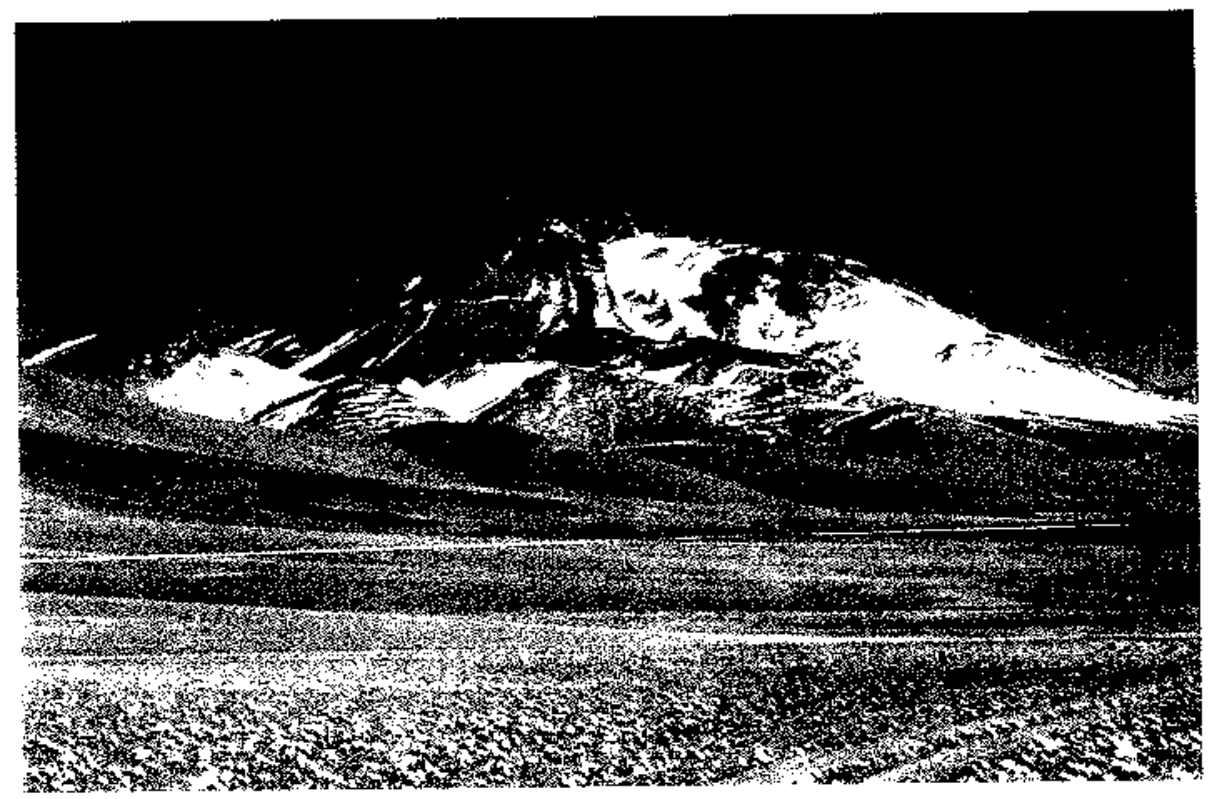

Figura 3. El Llullaillaco visto desde el Norte.

Figure 3. Mt. Lullaillaco from North.

El volcán está compuesto de tres lavas de edades diferentes. La base consiste en cuarzo-biotita-dacitas del Plioceno al Pleistoceno temprano, sobre los cuales se han derramado dos lavas más jóvenes. La más antigua de éstas es de 41.000 años de edad y también está formada por cuarzo-biotita-dacitas. La lava más joven, consistente en homblenda-dacitas, se solidificó hace 5.600 años.

\section{Circulación atmosférica y clima}

Como ya se mencionó, aún no existe una extensa secuencia de datos climáticos de la cercanía del Llullaillaco, de manera que se puedan deducir las condiciones climáticas a partir de un gran número de trabajos hechos en la zona de estudio. Mencionemos, sin embargo, los valiosos trabajos recientes de ENDLICHER (1983), HOFFMANN (1992), RICHTER $(1995,1996) \mathrm{y}$ VUILLE (1996).

El Llullaillaco se encuentra en la zona de transición entre las circulaciones tropical y extratropical. Las precipilaciones estivales convectivas (diciembre a 
febrero) e invernales advectivas (junio a agosto) alcanzan la zona central del eje andino, de máxima aridez, sólo esporádicamente. Sin embargo, en escasas ocasiones puede darse el caso de que masas de aire húmedo se desplacen a través de y mucho más allá de la diagonal de máxima aridez.

El anticiclón del sudeste del Pacífico, que permanece relativamente estable durante todo el año, es responsable de la aridez excepcional en los alrededores del Llullaillaco. Aparte de esto, a lo largo de la costa chilena, la corriente de Humboldt traslada aguas frías de la Antártida hacia el norte hasta la costa peruana. En este trayecto, la corriente enfría las masas de aire que poseen poca humedad y reduce la evaporación, de manera que sólo masas de aire extremadamente seco pueden entrar al interior del país. Particularmente durante los meses de verano, cuando el anticiclón del sudeste del Pacífico está en su posición meridional máxima, un desplazamiento de aire húmedo marítimo desde oeste es casi imposible. Durante estos meses, sin embargo, se producen fuertes procesos de convección sobre el altiplano, causados por el calentamiento de las altiplanicies en el interior de Ios Andes. El anticiclón local llamado Boliviano, conduce masas de aire húmedo a lo largo del cordón principal andino hacia el sur. VUILLE (1996) estima que a $18^{\circ} \mathrm{S}$ y $4.000 \mathrm{~m}$ de altitud aún caen precipitaciones medias anuales de $600 \mathrm{~mm}$. A $23^{\circ} \mathrm{S}$ y la misma altitud sólo llegarían $150 \mathrm{~mm}$, siendo todavía el $80 \%$ precipitaciones estivales.

El invierno del hemisferio Sur empieza con una intensificación de los vientos del oeste zonales en la troposfera superior. El anticiclón del sudeste del Pacífico se traslada lentamente hacia el norte. ENDLICHER (1983) indica la posición de su centro a aproximadamente $27^{\circ} \mathrm{S}$. Durante este desplazamiento, el anticiclón se debilita y se aleja bastante de la costa chilena. La consecuencia es que áreas de baja presión o enteros sistemas frontales desacoplados pueden avanzar bastante hacia el norte. VUILLE (1996) menciona la latitud de $20^{\circ} \mathrm{S}$ como límite septentrional de los sistemas frontales invernales. En vista de que la trayectoria media de ciclones invernales pasa por una latitud de $42^{\circ} \mathrm{S}$, una desviación tan marcada significa que la advección del aire frío sobre el desierto de Atacama debe ir acompañada de altas velocidades del viento. ACEITUNO (1989) habla de $30 \mathrm{~m} / \mathrm{s}$. Si luego despega una masa de aire tropical de una capa más baja y que todavía está caliente, se producen precipitaciones intensas (ARAVENA et al., 1989). Sin embargo, esas precipitaciones en las cercanías del Llullaillaco siempre son eventos esporádicos, 10 que dificulta indicar las precipitaciones medias anuales. En contraste con lo dicho anteriormente, el lado argentino permanece seco. El cordón principal andino actúa como una barrera para el vapor (WEISCHET, 1988). Por lo tanto, los meses de invierno son aún más secos que en el lado chileno. 
PIRINEOS 155

\section{Vegetación}

Según RICHTER (1996), el Llullaillaco muestra la menor cubierta vegetacional de las zonas altas del desierto de Atacama, pero su presencia se parece mucho a la del Volcán Socompa (6.062 m), a unos $60 \mathrm{~km}$ al nordeste. En consecuencia, por razones fitogeográficas hay que suponer que el eje andino de máxima aridez cruza la Cordillera Alta en el Llullaillaco o insignificantemente más al norte. La vegetación comienza entre los 3.700 y $3.800 \mathrm{~m}$ de altitud con Acantholippia punensis, Atriplex imbricata y Cristaria andicola. Esto indica que más abajo, el clima debe ser más árido. Las coberturas vegetacionales extraordinariamente bajas que, a excepción de las vegas, no sobrepasan el 12 $\%$, son las más bajas del piso alto de Atacama. La cobertura máxima es alcanzada a los $4.250 \mathrm{~m}$ de altitud. Ahí se encuentran —además de Stipa frigida, que es ubicua entre los 3.900 y $4.910 \mathrm{~m}-$ Mulinum crassifolium, Adesmia spinosissima, Parastrephin quadrangularis y Fabiana bryoides. La disminución de la cobertura vegetacional desde los $4.250 \mathrm{~m}$ hacia arriba no se debe necesariamente a un aumento en la aridez, sino que más bien al descenso de temperatura, tal como pudimos observar in situ en inviemo y verano tardíos. Esto también se reafirma por el hecho de que con la transición a la zona de lluvias invernales, el número de especies y la cobertura vegetacional siguen disminuyendo. Así, por ejemplo, la cobertura máxima de la vegetación entre Copiapó y el Paso San Francisco alcanza sólo aproximadamente el $4 \%$. Los fenómenos de solifluxión llegan hacia abajo hasta $\operatorname{los} 3.000 \mathrm{~m}$ de altitud, mientras que existen a partir de los $4.000 \mathrm{~m}$, aproximadamente, en el Cerro Sillajhuay (5.982 m) a $19^{\circ} 45^{\prime} \mathrm{S}$ en la zona de lluvias estivales de la Cordillera Alta.

\section{Geomorfología del Volcán Llullaillaco}

\subsection{Morfografin}

El levantamiento de la morfografía de las formas del meso-relieve se efectuó de manera simplificada siguiendo a KUGLER (1974). Los resultados se presentan en el Mapa Geomorfológico del Llullaillaco en la Figura 4.

Curvatura: Sólo se diferenciaron curvaturas convexas y cóncavas. No se aplicaron clasificaciones cuantitativas de las curvaturas. Cuando la curvatura cóncava resulta directamente del curso de una convexa, la primera no se dibujó. Esto ocurrió especialmente en el caso de curvaturas que acompañan un talweg. Interpretaciones genéticas derivadas directamente de la forma de 
las curvaturas, sólo son posibles en el caso de los piedemontes poco refocados. Dado que las divisorias de aguas entre dos talwege son más aplanadas y por lo tanto más difíciles de determinar cuanto más lejos están del cono volcánico, sólo quedan las líneas de curvatura convexa como características de las formas de meso-relieve en los piedemontes. Estas líneas, aunque sus radios de curvatura pocas veces son menores que $200 \mathrm{~m}$, generalmente se encuentran muy cerca de los talwege. Esto se debe a que la disección fluvial de los piedemontes era de poca duración y fue paulatinamente disminuida por la acción de la criodenudación y crioplanación. Cuanto más tiempo funciona el proceso, más se desplaza la línea de curvatura hacia el talweg, agrandando el radio de curvatura al mismo tiempo.

Escarpes, crestas: Ambas formas se caracterizan por un cambio abrupto de pendiente en el terreno (radio de curvatura menor que $6 \mathrm{~m}$, según KUGLER, 1974). En el caso del escarpe, esto sucede hacia un solo lado, en el caso de la cresta por ambos lados, produciéndose una divisoria de aguas afilada. Los escarpes y crestas se deben exclusivamente a procesos endógenos y a las propiedades estructurales de la roca. En muchos casos tienen su origen en las condiciones concretas de enfriamiento de la lava, independientemente de si se trata de volcanismo del Mioceno, Plioceno, Pleistoceno u Holoceno. Los escarpes de gelifracción, de génesis diferente, no fueron asociados a los escarpes y crestas (véase la leyenda del Mapa Geomorfológico del Lluliaillaco, Figura 4).

Divisorias de aguas: Las divisorias de las aguas no fueron representadas casi nunca porque en la mayoría de los casos se pueden deducir de las líneas de talweg y curvatura. Las pocas divisorias de aguas representadas se refieren a formas convexas sin cresta, constituidas por roca volcánica generalmente de mayor edad, o a nichos de despegue de diferentes movimientos en masa que produjeron el socavamiento de unidades de relieve originalmente planas.

Formas de valle: Se diferenciaron valles en $\mathrm{V}$, en cuna (con vertientes de pendiente débil o fuerte) y de fondo plano. Además se registró si los valles son rellenados disimétricamente y muestran una disección secundaria. Por otra parte se observó que los valles en $V$ sólo existen donde haya una base local de erosión de nivel bajo. La disección por erosión regresiva sólo se presenta de modo incipiente. Valles de fondo plano sólo existen en las áreas de nichos de despegue, o sea, formados por el lavado a partir de cursos de corrientes de barro. La forma de valle que predomina es la del valle en cuna, que existe en los piedemontes antiguos igual que en los sedimentos más jóvenes provenientes de movimientos en masa. Es interesante que especialmente en el sudeste, en concordancia con las zonas que no tienen una red de drenaje dendrítico, los valles en cuna muchas veces presentan vertientes menos inclinadas. Sin embargo, estos valles en cuna menos disección no son la consecuencia de 
aplanamiento en extensión, como BÜDEL (1977) lo describe, sino que se deber a la falta de diseccción fluvial. Esto se puede sostener a pesar de que los procesos fluviales generalmente experimentan una intensificación de la eficacia bajo mayor aridez porque por un lado, la cubierta vegetal se reduce y por el otro, los caudales máximos aumentan; lo decisivo es que las masas deslizadas. en las que existe la red de drenaje no completo, son el sedimento singenético de las volcanitas más jóvenes del Llullaillaco. Dado que estas volcanitas se derramaron sobre la forma de meso-relieve de los glaciares de fondo ancho ${ }^{2}$ ("Breitbodengletscher, wide bottom hollows" según LEHMKUHL, 1991/1992); véase también la última sección), se puede suponer una edad que debe situarse en el Tardiglacial. En efecto, la edad de las lavas es de 5600 años, según lọ análisis del helio cosmogénico ${ }^{3}$. En este lapso de tiempo se pueden desestimar aplanamientos en el sentido de BÜDEL (1977).

Talwege: Cuando el modelado entre dos divisorias de las aguas muy aplanadas no correspondía a las formas de valle mencionadas, se marcó el curso de los puntos de relieve más bajos como talweg. En su mayor parte se trata de formas cuya pendiente es superior a la mitad de la que poseen las vertientes correspondientes (LOUIS \& FISCHER, 1979), pero no siempre era posible usar esta definición de manera estricta, especialmente en las áreas de nichos de despegue y de transición a surcos de erosión.

\subsection{Superficies de formación autóctona}

Las lavas holocentas casi no están afectadas por procesos autóctonos. Aún conservan como forma superficial tas estructuras de enfriamiento producidas durante su solidificación. Esto igualmente se aplica a las lavas en blogues. Éstas también están constituidas por volcanitas holocenas. En el proceso de enfriamiento se formaron bloques sueltos que actualmente se pueden encontrar in situ encima de la lava, o fueron movidos por la gravedad durante o inmediatamente después del enfriamiento. Las lavas en bloques que corresponden a efusiones más antiguas, están parcialmente cubiertas de cenizas. Por lo tanto, las cubiertas de ceniza no afectadas indican una formación autóctona.

Por otra parte, existen los escombros en bloques, que fueron desplazados por la gravedad después del enfriamiento. Se trata principalmente de material muy grueso que fue depositado en concavidades de la vertiente o al pie de la misma y ha experimentado desde entonces un retocamiento autóctono.

2 Los glaciares de fondo ancho son glaciares frios que no han producido un circo, sino que sólo han alisado la superficie. Precisan temperaturas muy bajas y alimentación escasa.

3 Se agradecen las dataciones al Dr. Tibor J. Dunai de la Facultad de Ciencias de la Tierra de la Universidad de Amsterdam.

12 
Las superficies de gelifracción tienen una estructura completamente diferente (Figura 5). Se trata de volcanitas miocenas y pliocenas meteorizadas in situ, que se encuentran fuera de la zona de las volcanitas Llullaillaco I de la cumbre principal. El resultado son gelifractos angulosos que se caracterizan por ejes longitudinales largos y ejes en profundidad muy cortos. Los ejes transversales generalmente no presentan una tendencia clara. Los escombros de gelifracción son casi exclusivamente inmóviles. Las superficies de gelifracción están parcialmente cubiertas de cenizas de las erupciones cuaternarias Llullaillaco I y II (GARDEWEG, RAMIREZ \& DAVIDSON, 1993), pero los componentes de los gelifractos tienden a desplazarse en las cenizas. En altitudes elevadas, aproximadamente a partir de los $5.400 \mathrm{~m}$ de manera bastante clara, los procesos de lavado toman parte en el modelado de las superficies de gelifracción cubiertas de cenizas.

Por encima de los $6.000 \mathrm{~m}$ de altitud, existen grandes áreas de nevé y hielo quebrado. Éstos se encuentran principalmente en depresiones que sirvieron durante los períodos fríos como zona de acumulación de los glaciares fríos. Producto de la alta evaporación, principalmente se conservaron restos de penitentes de nieve inmóviles, cuya influencia sobre las formas de la superficie debería ser insignificante (Figura 6). En la parte superior del campo de

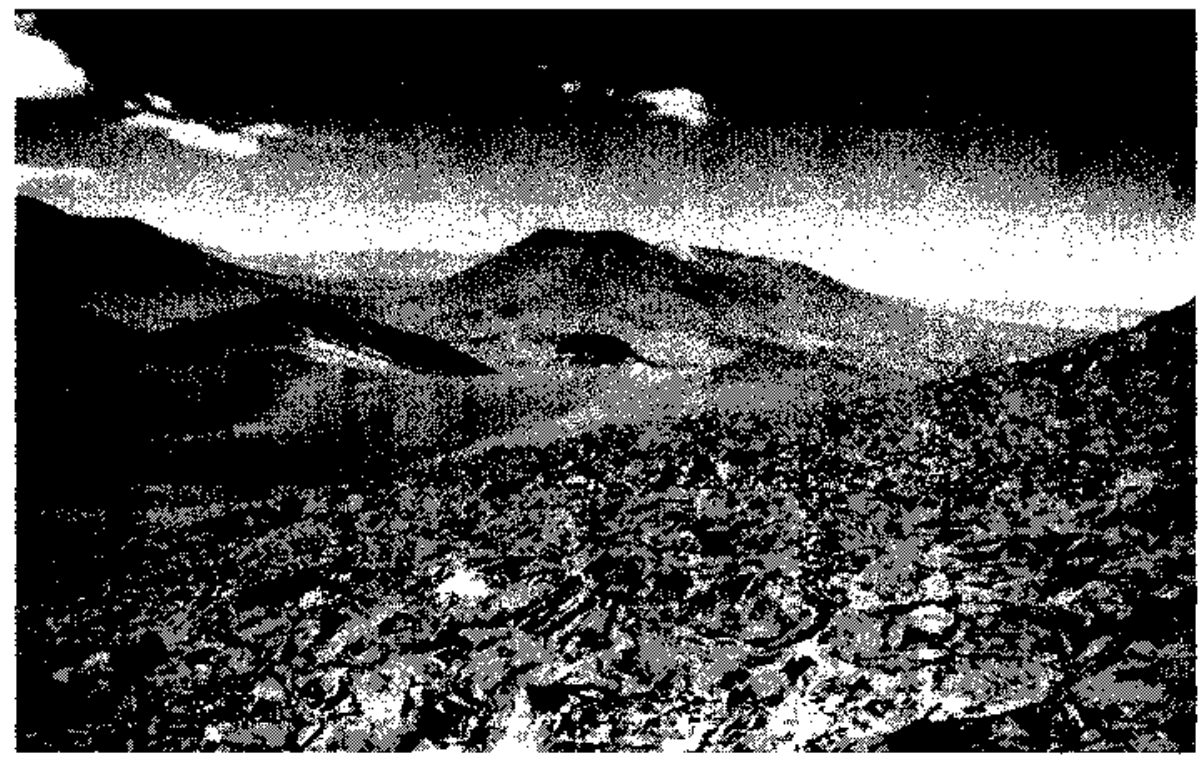

Figura 5. Superficies de gelifracción a los $4.800 \mathrm{~m}$ de altitud Figure 5. Congelifraction surface at $4,800 \mathrm{~m}$ a.s.! 


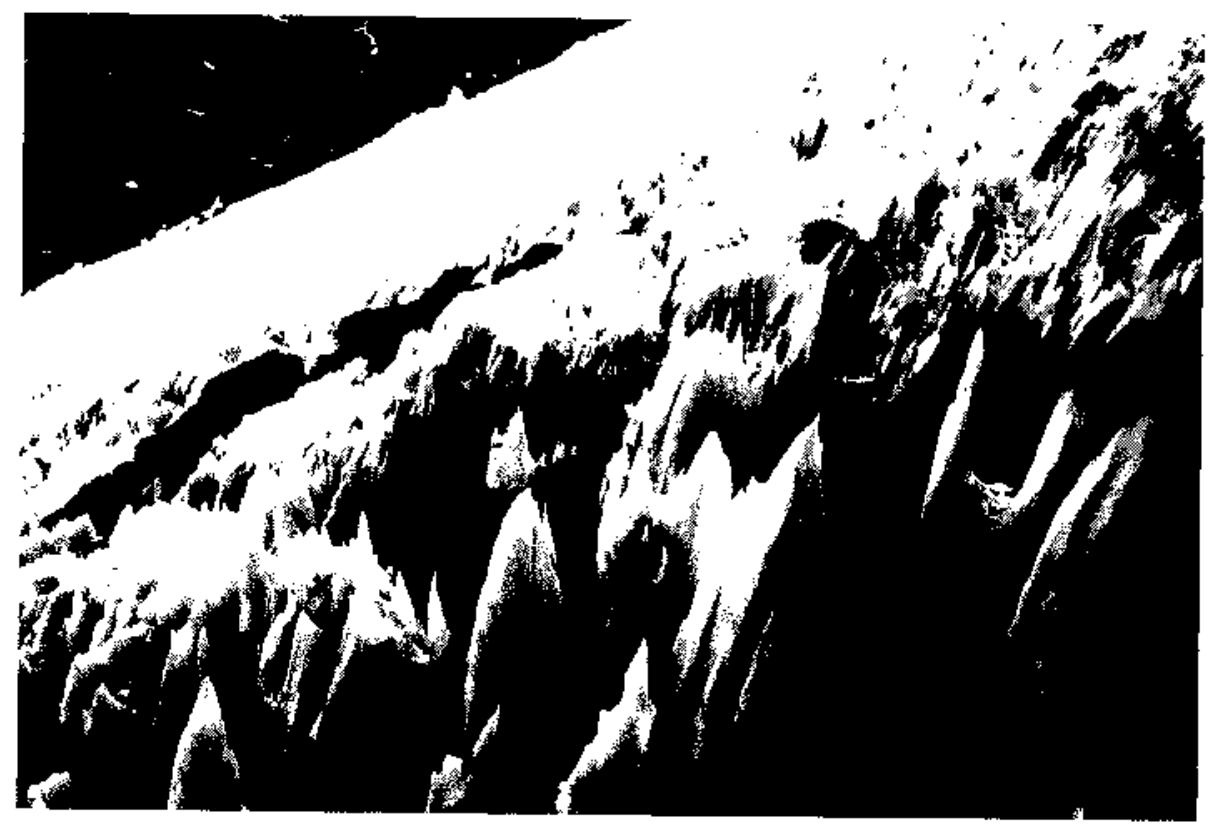

Figura 6. Penitentes de nieve a los $6.000 \mathrm{~m}$ de altitud. Figure 6. Pentifent ice af 6,000 m a.s.l.

hielo quebrado, a $6.300 \mathrm{~m}$ de altitud, tampoco se pudieron observar indicios de desplazamientos recientes de las masas de hielo (como material no consolidado deformado, por ejemplo).

Una particularidad de las superficies de formación autóctona son los tores de roca. Se trata de formas de meteorización de rocas que se elevan sobre las superficies de acumulación; generalmente se presentan en tropeles, raras veces solas. En esas formas, se pueden diferenciar claramente dos tipos de meteorización: una más antigua, sin duda predominantemente química, que ha producido formas más redondeadas e indica condiciones relativamente cálido-húmedas; y otra la gelifracción reciente que conduce a la destrucción de los tores de roca (Figura 7).

\subsection{Superficies de formación alóctona}

\subsubsection{Formas periglaciales}

Los lóbulos de solifluxión son las formas periglaciales más destacadas y extendidas. Empiezan con formas muy pequeñas y aisladas en superficies 


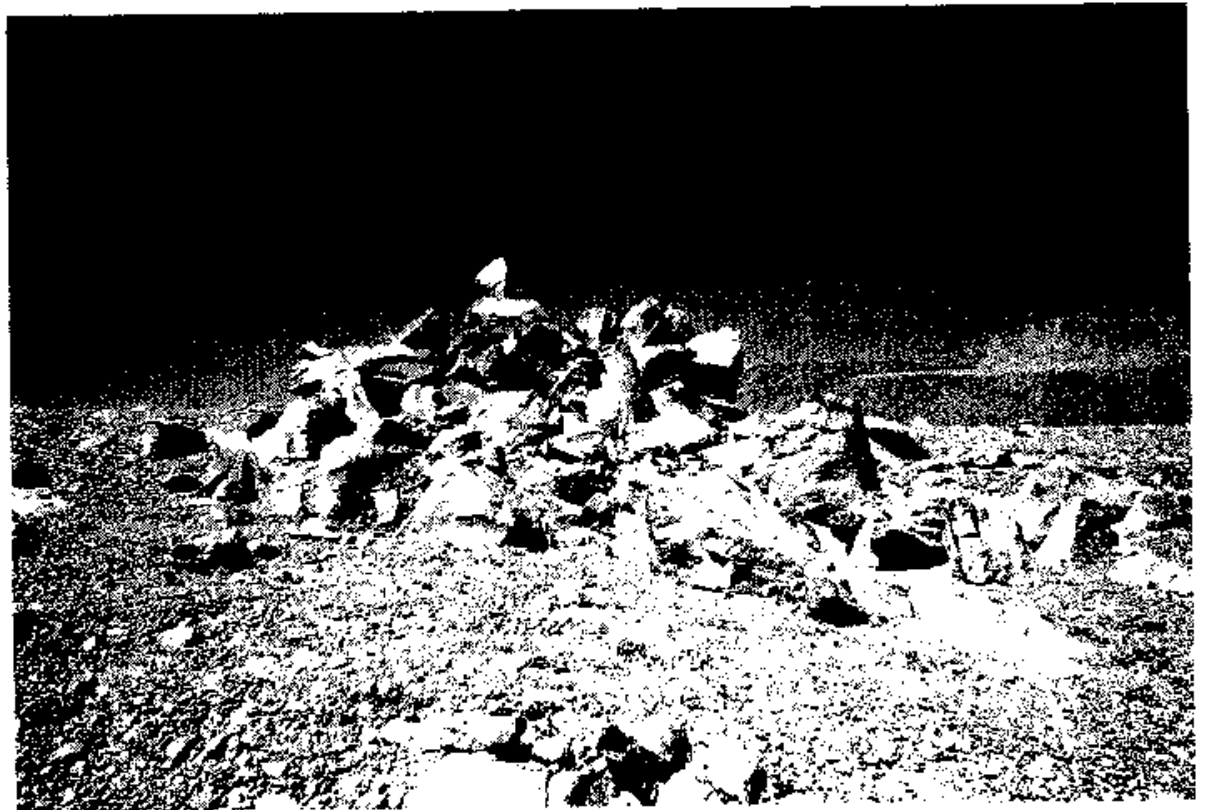

Figura 7. Tor de roca a los $4.700 \mathrm{~m}$ de altitud.

Figure 7 . Rock tor af $4,700 \mathrm{~m}$ a.s.t.

planas de pendiente débil por encima de los $4.500 \mathrm{~m}$, aproximadamente. Alcanzan mayor extensión en el lado chileno a $4.800 \mathrm{~m}$ de altitud, y en el lado argentino hacia el sudeste, a unos $300-400 \mathrm{~m}$ más arriba. En el lado chileno, las formas más marcadas se encuentran entre los 5.100 y $5.400 \mathrm{~m}$ de altitud. Más arriba, el tamaño disminttye, pero aún se observan lóbulos de solifluxión hasta los $6.300 \mathrm{~m}$ de altitud en las superficies de gelifracción lavadas.

Asociados a las formas de la solifluxión están los bloques-presn (Blockstau, block ramparts), que en contraste con otras formas del clima hiperárido se presentan en extensión, pero también como formas aisladas de apariencia destacada. Esta forma se produce por el proceso denominado apresamiento por bloques, o sea, cubriéndose grandes bloques por material más fino desplazado superficialmente (Figura 8). El apresamiento por bloques se debe a ciclos de hielo-deshielo en el curso del día. El permafrost no juega ningún papel o

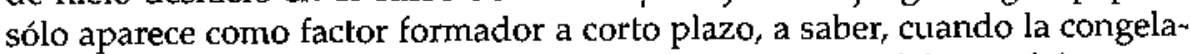
ción del suelo se retira en las horas del mediodía hasta el frente del permafrost. Esto sólo ocurre en diciembre, enero y eventualmente a comienzos de 


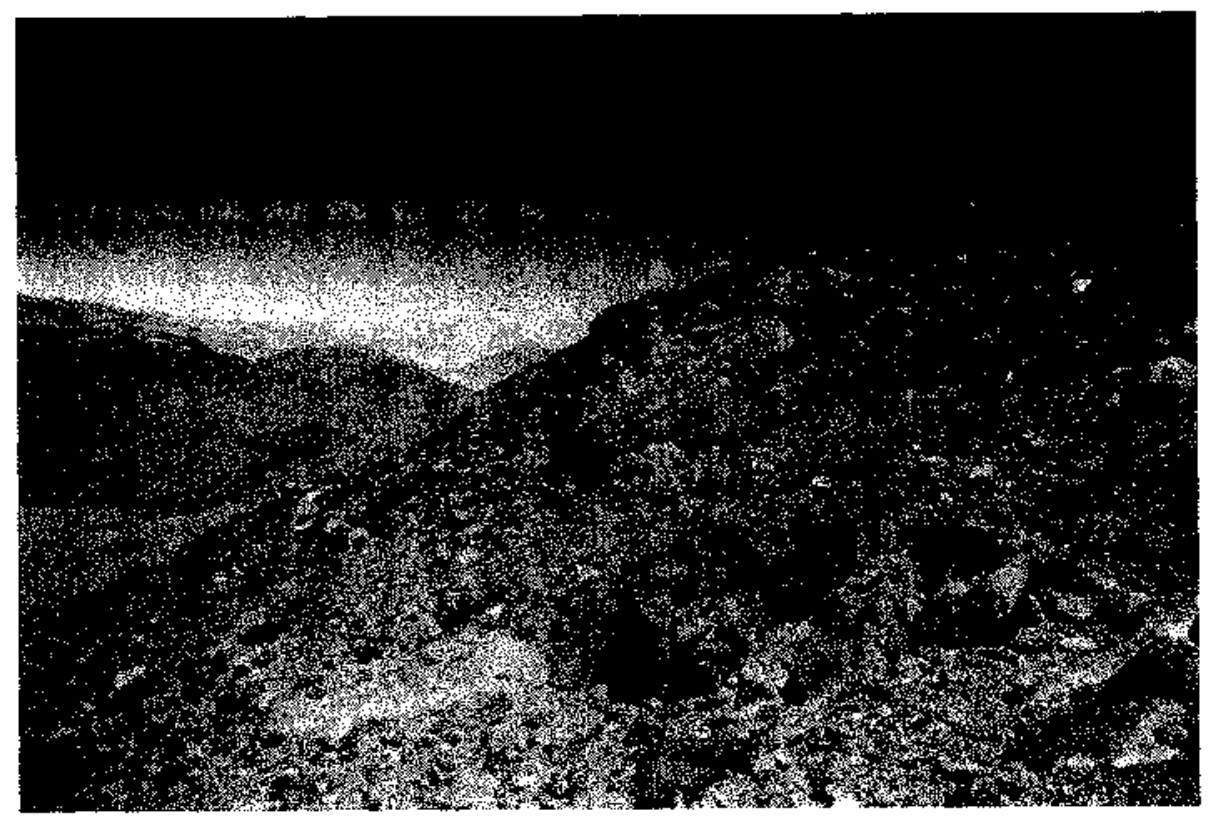

Figura 8. Bloque-presa a los $5.200 \mathrm{~m}$ de altitud. Figure 8. Block rampart at $5,200 \mathrm{~m}$ a.s.

febrero. Durante los demás meses, el nivel de deshielo diario no alcanza el frente del permafrost, sino que en parte queda claramente más arriba de éste. Los bloques gruesos en su mayoría permanecen en este frente de helada, mientras que bloques más pequeños y especialmente el material fino quedan descongelados entera y diariamente. A pesar de que la escasa humedad conduce a desplazamientos ladera abajo relativamente débiles, por ejemplo en forma de flujos de material saturado de agua, las alternancias de hielo-deshielo casi diarias aseguran un transporte prácticamente continuo en la superficie. Los bloques-presa de mayor espesor, ubicados entre los 5.000 y $5.100 \mathrm{~m}$ de altitud, coinciden con el piso de las mayores frecuencias de hielo-deshielo, que casi alcanzan ritmo diario durante todo el año. La intensidad disminuye hacia arriba y hacia abajo. Ladera abajo, esto se debe al menor número de días con hielo-deshielo por año, a la humedad disminuida y a la pendiente reducida como consecuencia de la forma de mesorelieve del volcán. La importancia de esto túltimo radica en que a partir de los $4.400 \mathrm{~m}$ de altitud, aproximadamente, los bloques-presa no existen en superficies planas de débil pendiente, mientras que en los taludes de las vertientes de valles aún se presen- 
tan bloques-presa marcados a $4.100 \mathrm{~m}$ de altitud. Sin embargo, su límite inferior en las superficies de mayor pendiente es muy abrupto. A los $4.000 \mathrm{~m}$ de altitud en la Quebrada de las Zorritas ya no se encontraban bloques-presa. Hacia arriba, la disminución de la altitud de las terrazas de bloque-presa se debe a dos causas: Por una parte, excavando se comprobó la menor profundidad del frente de permafrost (a los $5.400 \mathrm{~m}$ de altitud unos $50 \mathrm{~cm}$, a los 5.800 $\mathrm{m}$ unos $30 \mathrm{~cm}$ ), y por otra parte, el número de días con alternancias de hielodeshielo disminuye, produciéndose cada vez más días de hielo.

La criodenudación es un fenómeno que muy probablemente está restringido a ambientes periglaciales de los desiertos hiperáridos. Este proceso existe en un piso altitudinal bastante estrecho entre los 4.300 y $4.500 \mathrm{~m}$, y reemplaza la solifluxión ladera abajo. Sin embargo, aún en este piso se insinúa el apresamiento por bloques. La criodenudación no engendra formas superficiales periglaciales. Su presencia se puede deducir indirectamente de las acumulaciones en aquellos valles que tienen un relleno de sedimentos. Ahí se observa claramente que sedimentos de vertiente desplazados por la denudación son acumulados sobre depósitos fluviales de edad cualquiera. Dado que este cubrimiento también se ha producido sobre cuerpos de acumulación muy jóvenes y sobre las vertientes inferiores cóncavas y de débil pendiente, todo el proceso se debe haber desarrollado en tiempos subrecientes y muy probablemente aún en tiempos recientes, aunque en estos últimos probablemente con menor intensidad. El proceso se puede explicar de la siguiente manera: bajo las condiciones de extrema aridez en el piso base, las alternancias de hielo-deshielo - que todavia son muy frecuentes-ya no son capaces de originar el impacto decisivo sobre las formas superficiales. La poca humedad, que no obstante está presente, en conjunto con la gravedad causa en superficies inclinadas planas un desplazamiento superficial que disminuye hacia mayores profundidades. Entonces, la superficie es rebajada paralelamente a si misma por efecto de las heladas. Por lo tanto, este proceso puede ser denominado criodenudación, y su resultado es un aplanamiento debido al hielodeshielo en el piso base periglacial seco en desiertos hiperáridos.

Entre los $4.400 \mathrm{~m}$ y $5.500 \mathrm{~m}$ de altitud, aproximadamente, en el marco de un frío creciente, altemancias de hielo-deshielo más intensas y una humedad baja, pero suficiente, y por lo tanto cubiertas de nieve esporádicas, se produce la crioplanación, un proceso de aplanamiento denudativo periglacial, que se desarrolla independientemente de la base local de erosión (BRYAN, 1946; DEMEK, 1968; KARRASCH, 1972; WEISE, 1983). Debido a la baja cobertura vegetal, la crioplanación en el Llullaillaco siempre está asociada a formas de deflación y en consecuencia a la formación de pavimentos. Esto también ocurre en otras zonas altitudinales, pero con diferentes intensidades, por lo cual el notable aplanamiento es la consecuencia de la crioplanación (Figura 9). El 
tamaño de las terrazas de crioplanación depende directamente de la formación del meso-relieve, y las terrazas terminan en el límite con las volcanitas Llullaillaco o con masas deslizadas del Holoceno. Las terrazas tienen una anchura de varios cientos de metros en paralelo a la pendiente y una longitud de varios kilómetros en paralelo a las curvas de nivel. Los ejemplares ininterrumpidos más grandes se observan en el collado meridional. Se pueden comparar sus formas con los criopiedemontes marginales (Randkryopedimente) descritos por DEMEK (1968) y WEISE (1983). Se puede observar tna orientación marcada del eje en prohindidad de los componentes de escombros: El eje más corto de los tres ejes principales está orientado de manera vertical, mientras que los ejes Iongitudinal y transversal no presentan ninguna tendencia clara de su orientación. Da la impresión de que los componentes más gruesos de los escombros «flotan" sobre un fondo más rico en cenizas y protegido de la deflación. A las terrazas de crioplanación están intemamente asociados bloqules-presa, y hacia mayores altitudes, terrazas de solifluxión y la formación de vertientes rectilíneas. Es posible establecer un límite hacia las terrazas de soli-

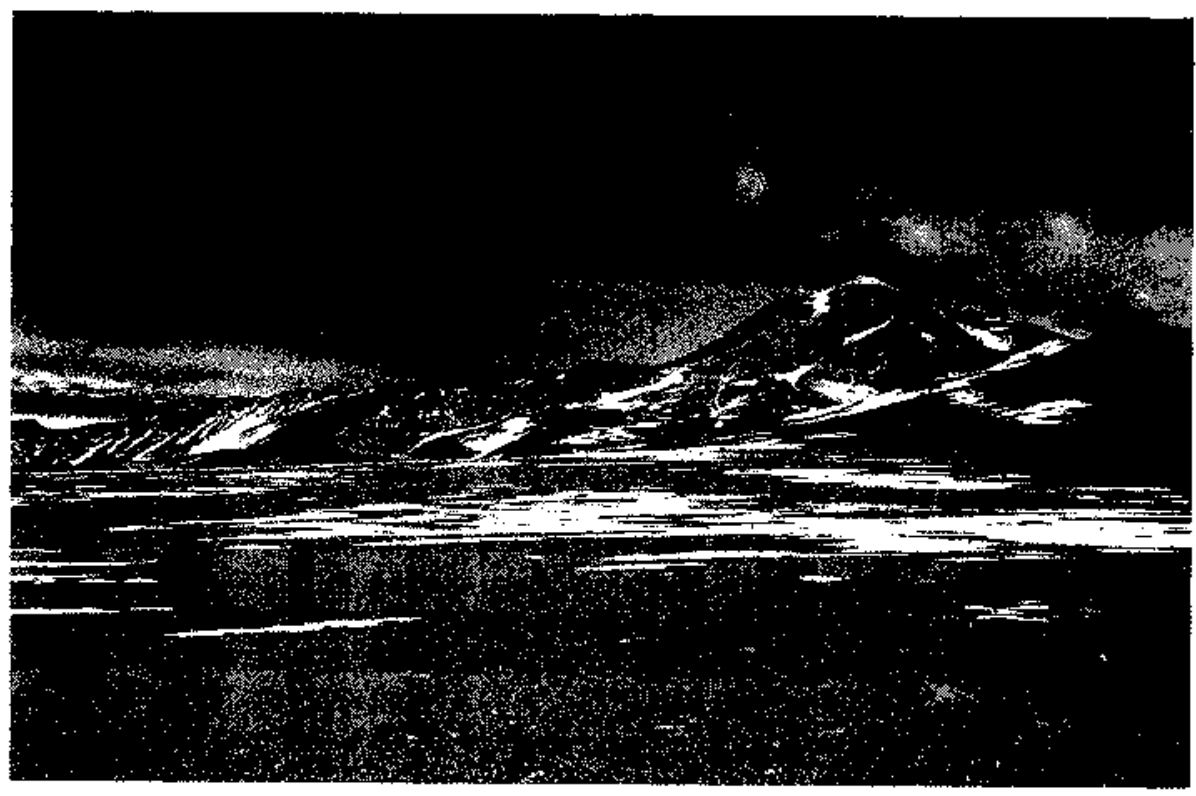

Figura 9. Crioplanación en una superficie cubierta de escombros con una pendiente de $2-4^{\circ}$; collado meridional en el lado chileno a $4.800 \mathrm{~m}$ de altitud.

Figure 9. Cryoplanation of a debris-covered, $2-4^{\circ}$ inclined surface on the Chilean south saddle at 4,800 m a.s. $L$. 
fluxión mediante una franja de 100 a $200 \mathrm{~m}$ de ancho. Las transiciones hacia la formación de vertientes rectilíneas, al contrario, son muy difusas y principalmente dependientes de la pendiente, de manera que en la mayoría de los casos, el escarpe de gelifracción se encuentra a varios cientos de metros más arriba, sirviendo como intermedio la formación de vertientes rectilíneas.

El grupo siguiente de formas de relieve cartografiables desde la superficie, está relacionado con los fenómenos de crioturbación. Se pueden clasificar en franjas de piedras, suelos poligonales e hinchazones del suelo, pero hay una amplia gama de formas intermedias.

Los suelos poligonales o strelos estructurados son muy frecuentes en el Llullaillaco. Se pueden formar en todas partes donde haya una pendiente pequeña y un sustrato de granulometría heterogénea. El material queda ordenado según el tamaño de granos producto de las heladas. Cuando hay una gama relativamente amplia de tamaños (de bloques a arcilla) en el sustrato, en el caso ideal se desarrollan formas poligonales con un interior rico en material fino y un borde rico en material más grueso. El interior presenta un diámetro entre $\operatorname{los} 20 \mathrm{~cm}$ y $1,50 \mathrm{~m}$ como máximo. El borde generalmente tiene como ancho aproximadamente la décima parte del diámetro del interior del polígono. La profundidad de ordenamiento en la mayoría de los casos es pequeña y varia entre los 4 y $20 \mathrm{~cm}$. Cuando no está presente el material fino, se desarrollan megapolígonos cuyo interior mide varios metros en diámetro, pero cuyos bordes son muy estrechos. En este caso, el grosor del borde aicanza sólo un vigésimo a un cincuagésimo del diámetro del interior, y la profundidad de ordenamiento también es muy pequeña (Figura 10).

En el levantamiento sólo se podía aplicar un registro muy aproximado de los suelos estructurados. La gran diversidad de formas exige una investigación por separado de las regularidades en los fenómenos de suelos poligonales, especialmente con respecto a la zonificación altitudinal, pendiente, suministro de humedad, propiedades del sustrato etc.

Los suelos estriados pueden ser considerados como la variante de vertiente de los suelos poligonales (WASHBURN, 1979; WEISE, 1983). En el levantamiento sólo se diferenciaron franjas anchas y estrechas. En particular, las franjas estrechas (Figura 11) dependen de la intensidad de los ciclos de hielo-deshielo. Después de largos periodos secos, las formas se desdibujan en un tiempo relativamente corto.

Las franjas anchas, al contrario, son menos dependientes de las condiciones meteorológicas precedentes (Figura 12). Sin embargo, no se pueden excluir influencias estacionales. Eran reconocibles más fácilmente en septiembre/octubre de 1995, lo cual seguramente se debe a que en las partes más ricas en material fino, las sales llegan a la superficie y acentúan las estructuras, pero desaparecen después de períodos largos de sequía, supuestamente 
PIRINEOS 155

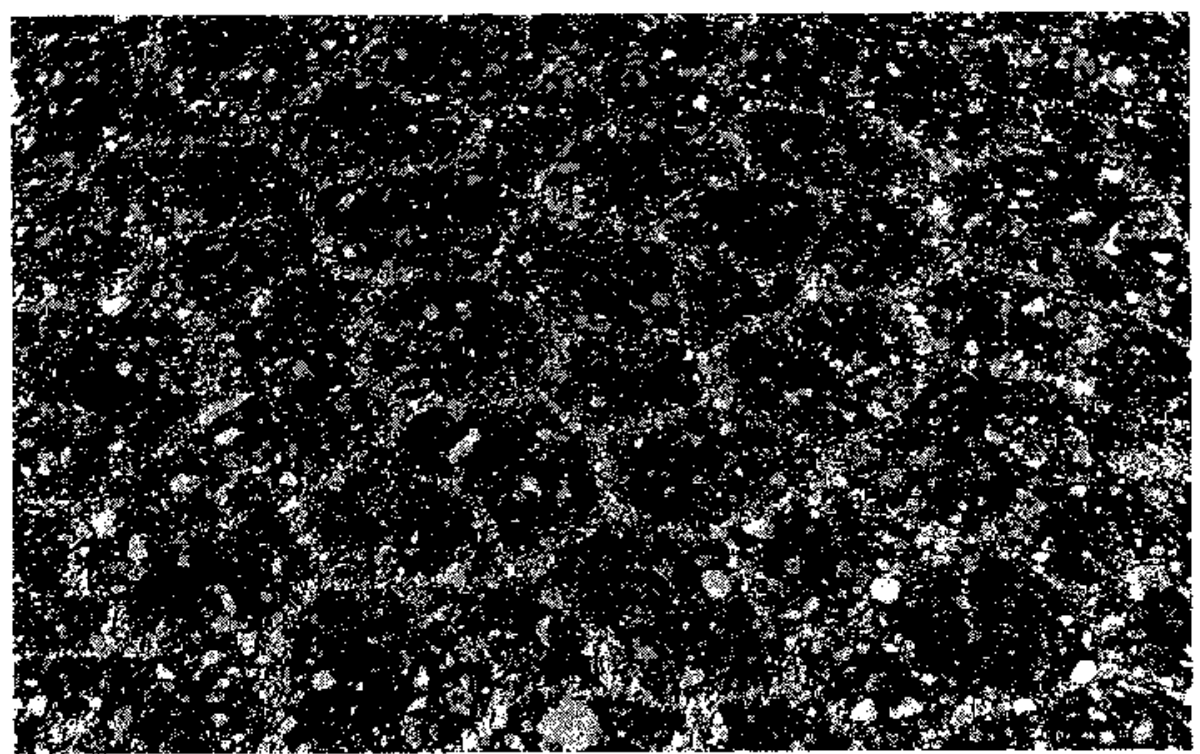

Figura 10. Suelos poligonales a $1054.800 \mathrm{~m}$ de altitud. Figure 10. Patterned ground at $4,800 \mathrm{~m}$ a.s.1.

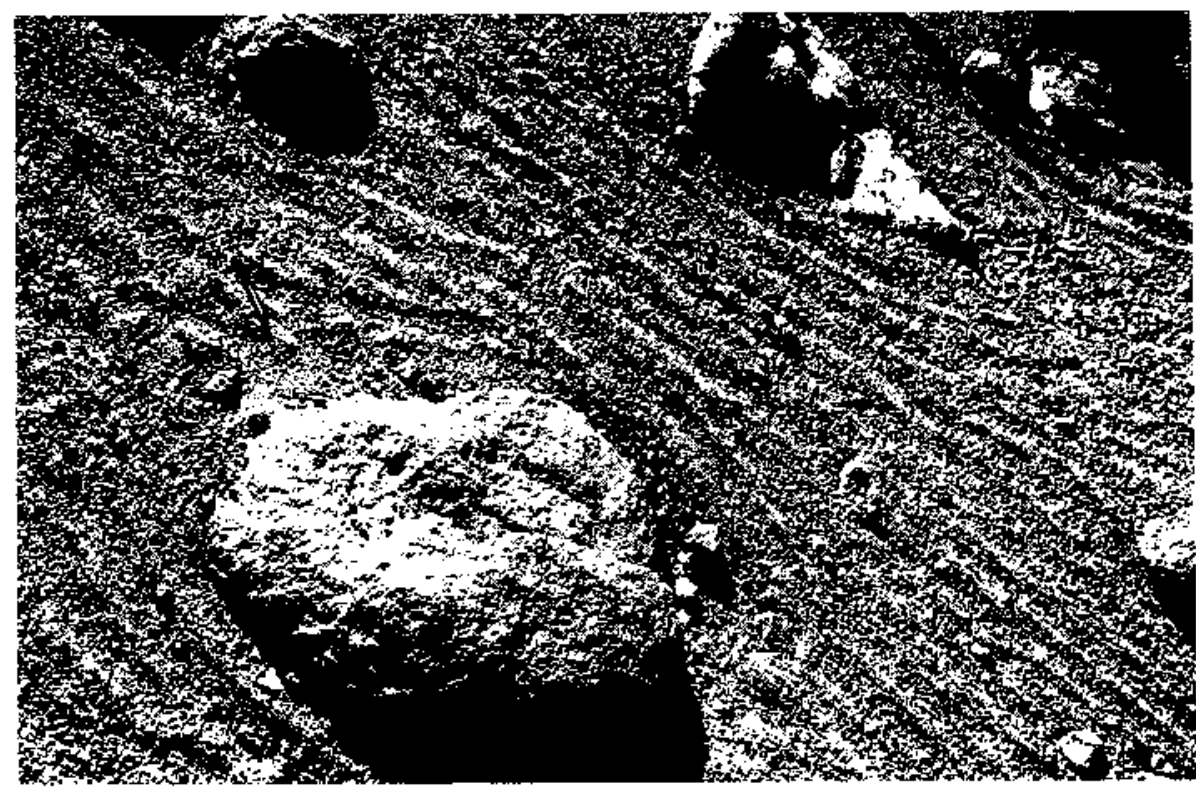

Figura 11. Suelos estriados a $1055.000 \mathrm{~m}$ de altitud.

Figure 11. Sfriped ground at 5,000 m a.s.l.

20 


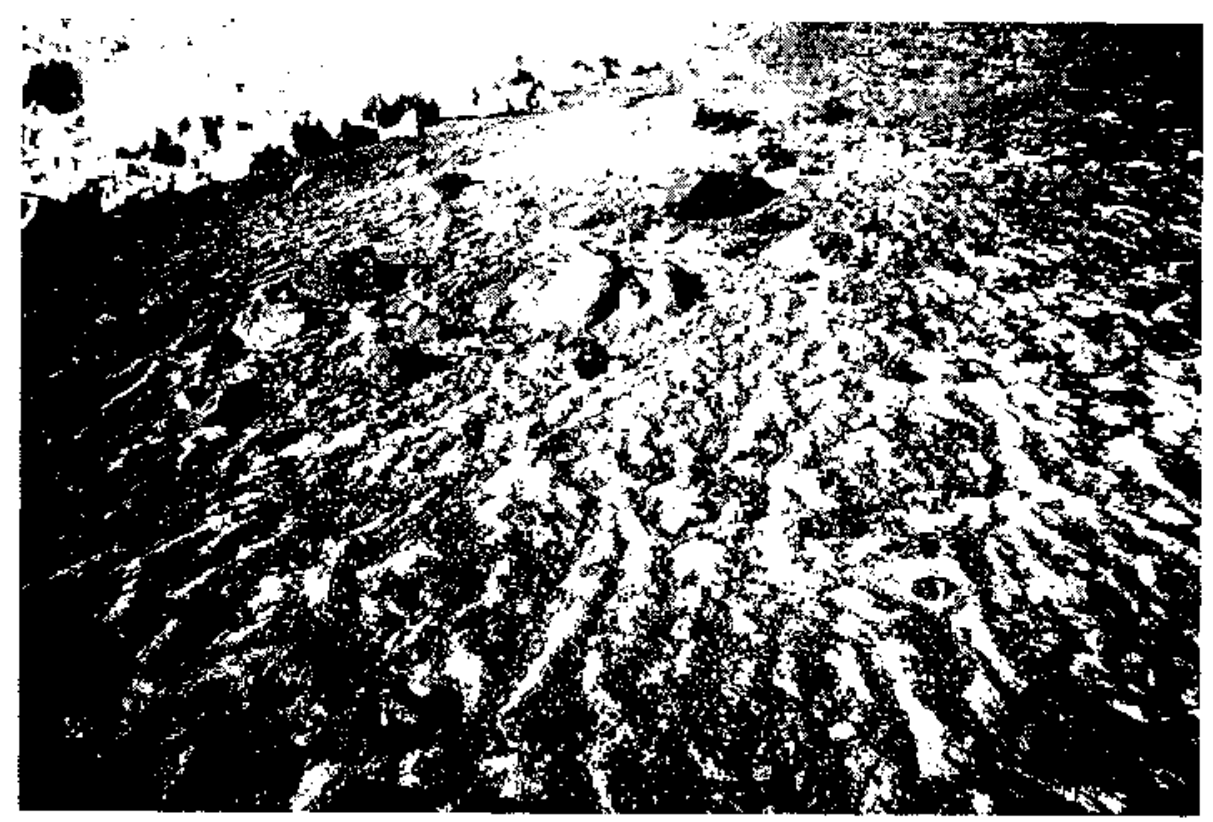

Figura 12. Franjas de piedra anchas a los $6.100 \mathrm{~m}$ de altitud. Figure 12. Pafferned striped ground at $6,100 \mathrm{~m}$ a.s.l.

debido a la deflación. También hacen falta investigaciones más detalladas de los suelos estriados que no pudieron ser objeto de la cartografía presente.

Una forma que está directamente relacionada con los suelos poligonales y estriados, son las hinchazones del suelo. Se presentan muy raras veces porque precisan un suministro suficiente de agua, y éste sólo existe esporádicamente. Las hinchazones sólo se podían observar asociadas a manchas de nieve. Al desaparecer las manchas de nieve, las hinchazones se reconvierten en un suelo poligonal ordinario.

De los $5.400 \mathrm{~m}$ de altitud hacia arriba en el lado noroccidental, chileno del Llullaillaco y a partir de los $5.700 \mathrm{~m}$ en el lado suroccidental, argentino, el espesor de los lóbulos de solifluxión disminuye notablemente, y al mismo tiempo se intensifican los fenómenos de lavado. Esta forma será denominada «terraza solifluidal lavada", ya que se distingue tanto de las terrazas de solifluxión marcadas a menores altitudes, como de las superficies de gelifracción lavadas a mayores altitudes.

La disminución del espesor de los lóbulos de solifluxión se explica por el levantamiento del frente de permafrost. Según comunicado verbal de 
SCHMIDT (Dresde), a $300 \mathrm{~km}$ más al norte en el Sairécabur y a $5.400 \mathrm{~m}$ de altitud, se encuentra el límite superior del permafrost a $50 \mathrm{~cm}$ de profundidad. En el Llullaillaco a la misma altura, el frente del permafrost está a $40 \mathrm{~cm}$ de profundidad. Se observaron profundidades de $50 \mathrm{~cm}$ a $\operatorname{los} 5.300 \mathrm{~m}$ de altitud. Ladera abajo, el nivel del permafrost cae rápidamente a mayores profundidades. A mayores altitudes, el frente permanece en profundidades entre los 30 y $40 \mathrm{~cm}$, lo que supuestamente estâ relacionado con las amplias oscilaciones diarias de las temperaturas del suelo. En particular, si la roca es oscura aumenta la temperatura superficial considerablemente. La amplitud de la oscilación estacional parece alcanzar magnitudes de sólo 10 a $20 \mathrm{~cm}$, aproximadamente, dado que en una excavación llevada a cabo en septiembre de 1995 a los $5.850 \mathrm{~m}$ de altitud, se encontró el frente de helada invernal a $30 \mathrm{~cm}$ de profundidad. ${ }^{4}$ Este comportamiento aparentemente contradictorio del frente del permafrost, se explica por que la amplitud diaria de la temperatura superficial del stelo excede mucho las amplitudes anuales. A modo de ejemplo, SCHMIDT (1995) registró oscilaciones medias diarias de $37^{\circ} \mathrm{C}$ (noche: $-19^{\circ} \mathrm{C}$, día: $+18^{\circ} \mathrm{C}$ ) en el Sairécabur en una altitud comparable. En cambio, las oscilaciones estacionales de las temperaturas medias diarias sólo varían entre $+1^{\circ} \mathrm{C}$ en verano y $-8^{\circ} \mathrm{C}$ en invierno. La existencia de un frente del permafrost a pocos decímetros debajo de la superficie tiene como consecuencia que los lóbulos de solifluxión son notablemente menos desarrollados. Sin embargo, al mismo tiempo aumenta el cubrimiento con material más fino. En la Leyenda del Mapa Geomorfológico (Figura 4), no sólo se diferenciaron áreas de pendiente fuerte y débil, lo que lleva a una diferenciación en la escorrentía superficial, sino tambiến se consideró la siguiente bipartición: Por una parte, se trata de lóbulos de solifluxión cuyas formas de lavado se internan en los bordes de material grueso, que se encuentran ladera abajo; por la otra, las formas de lavado exceden los bordes. En mayores altitudes, este último tipo predomina. Adicionalmente mencionemos que por encima de los $6.100 \mathrm{~m}$, aproximadamente, los lóbulos de solifluxión son remplazados por superficies de gelifracción, en las cuales se observan formas de lavado con al menos la misma intensidad. El piso de precipitaciones máximas de Atacama supuesto por RICHTER (1995) tiene que ser puesto en duda debido a los procesos formadores observados en el Llullaillaco.

Una forma de meso-relieve muy extendida en el Llullaillaco que, sir embargo, está restringida a volcanitas preholocenas, son las vertientes rectili-

4 El reconocimiento del frente del pernafrost se dificulla bajo las condiciones hiperáridas y de alta insolación en el Llullaillaco. Se uso como criterio el nivel del hielo compacto. En excavaciones en diferentes altikudes se pudo comprobar que los componentes más gruesos ya empiezan a cubrirse de hielo a niveles 10 a $15 \mathrm{~cm}$ más al tos. La causa de este fenómeno es la sublimación extraordinariamen te alta de hielo subsuperficial. 
nens. WEISCHET (1969) describió vertientes rectilíneas fósiles en el Norte Chico de Chile en el área de La Serena y el valle de Elqui. En el lado argentino, STINGL \& GARLEFF (1983) hicieron lo mismo. Ya que en los alrededores del Llullaillaco por encima de los $4.000 \mathrm{~m}$ de altitud, predominan los procesos periglaciales en el desarrollo del relieve, se trata de formaciones recientes de vertientes rectilíneas. Son vertientes uniformes, sin rupturas, y cuya curvatura en muchos casos điverge levemente. Con respecto a su dinámica, se encuentran en equilibrio en toda la vertiente; esto significa que la cantidad de material aportado a un punto es igual a la cantidad de material removido de este punto. En los alrededores del Llullaillaco, en la parte baja de las vertientes prevalece el aporte de material, porque la erosión fluvial es insuficiente. Ahí la vertiente rectilínea o evoluciona a una vertiente con solifluxión, 0 a formas de crioplanación, dependiendo de la altitud y la humedad disponible. En su parte superior, la vertiente rectilínea termina en un escarpe de gelifrncción. Ambos fenómenos forman una unidad morfogenética. No existe un escarpe de gelifracción cuando el desarrollo de la vertiente rectilínea ha alcanzado la divisoria de las agulas.

En la actualidad, las vertientes rectilíneas, en la mayoría de los casos, se consideran como formas periglaciales (cf. p. ej. BRETTSCHNEIDER, 1980; SCHRÖDER \& BERKNER, 1986). Sin embargo y evidentemente también hay condiciones de formación con poca o incluso sin influencia de procesos de hielo-deshielo (HAGEDORN, 1970; KELLETAT \& GASSERT, 1975). En este caso, las vertientes rectilíneas son el producto de la erosión hídrica sobre rocas que, debido a su estructura $o$ a la meteorización, presentan una alta permeabilidad hidráulica (diaclasas, cavidades por disolución). Bajo esas condiciones, la formación de drenes es frenada o impedida, porque se pierde agua superficial por infiltración. Por lo tanto, en la parte inferior de la vertiente está disponible menos agua superficial. Esto es por lo visto suficiente para desarrollar vertientes rectilíneas en períodos muy largos. Por eso la descomposición periglacial de las rocas no es necesariamente el proceso decisivo de la formación de vertientes rectilíneas. Sin embargo, al parecer la combinación de ambos procesos favorece una formación acelerada. Las volcanitas del Llullaillaco también pertenecen a las rocas de buena permeabilidad hidráuli$\mathrm{ca}$, de manera que se puede observar una elevada tendencia a la formación de vertientes rectilíneas.

Llama la atención el hecho de que las vertientes rectilíneas están mejor desarrolladas, cuanto más antiguos sean los materiales que las conforman. Las vertientes rectilíneas más marcadas se encuertran en las volcanitas miocenas y pliocenas al norte de la cumbre principal del Llullaillaco (Figura 13). Por lo tanto se puede excluir una glaciación, al menos en el ültimo periodo glacial, hasta los $5.300 \mathrm{~m}$ de altitud, porque en el caso contrario, uti desarrollo tan inten- 


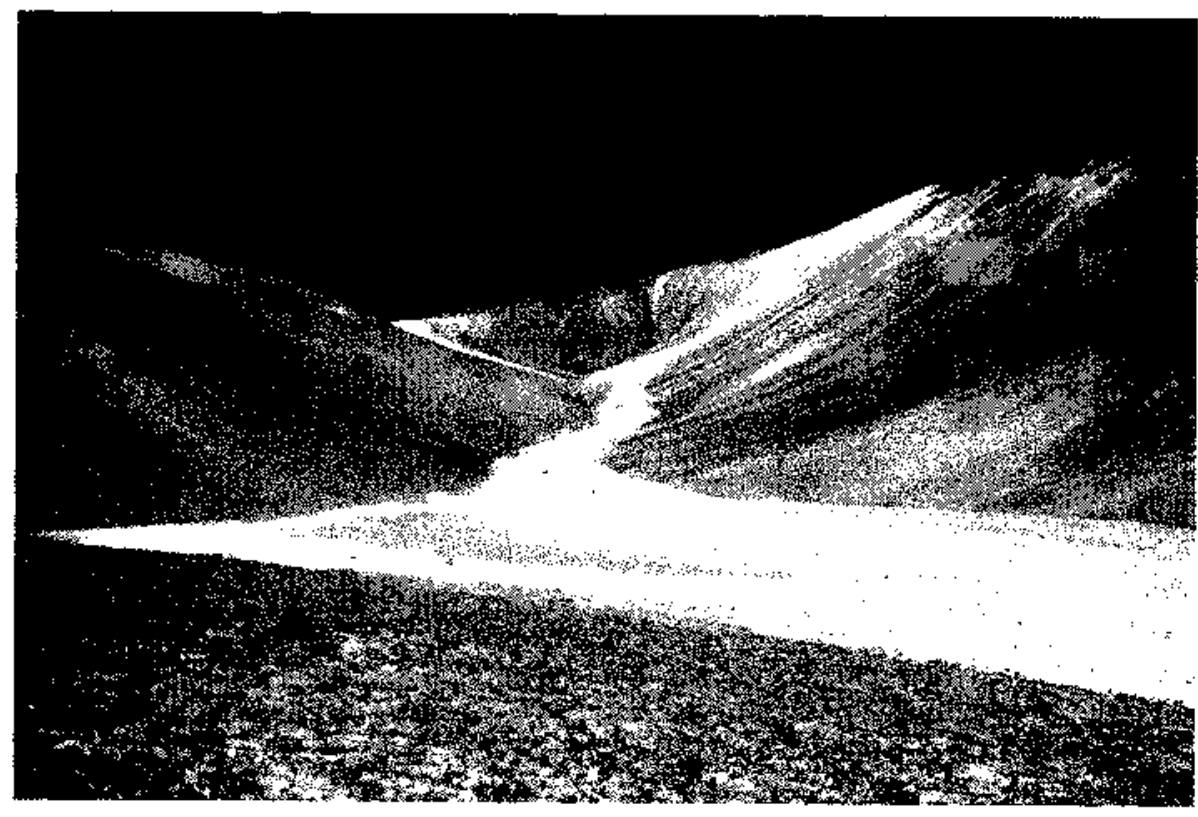

Figura 13. Vertientes rectilíneas entre 1054.900 y $5.300 \mathrm{~m}$ de altitud. Figure 13. Rectitinear slopes between 4,900 and 5,300 mt as.t.

sivo de vertientes rectilíneas no hubiera sido posible. En las volcanitas postglaciales, no es concebible ni una formación incipiente de vertientes rectilíneas, debido a que se precisan períodos muy largos para la formación de éstas.

La pequeña corriente de barro periglacial o criofujo de barro (Kryoschlipf) es otra forma particular del ambiente periglacial. Se trata de flujos generalmente singulares de material fino, que ocurren después del deshielo bajo cubiertas de nieve. Tienen que darse las siguientes condiciones: (1) El frente de helada estacional debe encontrarse sólo a pocos centimetros de profundidad. (2) El material que está encima, tiene que ser de granulometría fina, y (3) en un corto período, debe afluir relativamente mucha agua. En qué medida juega un papel la reducción de la temperatura de fusión por las sales disueltas en el agua que escurre sobre el frente de helada, queda pendiente para investigaciones más detalladas (cf. SCHRÖDER, MAKKI \& CIUTURA, 1996).

\subsubsection{Formas fluviales}

$\mathrm{Al}$ analizar la superficie del Llullaillaco en fotografías aéreas (Figura 14), llama la atención que en gran medida, el relieve es el producto de la acción 


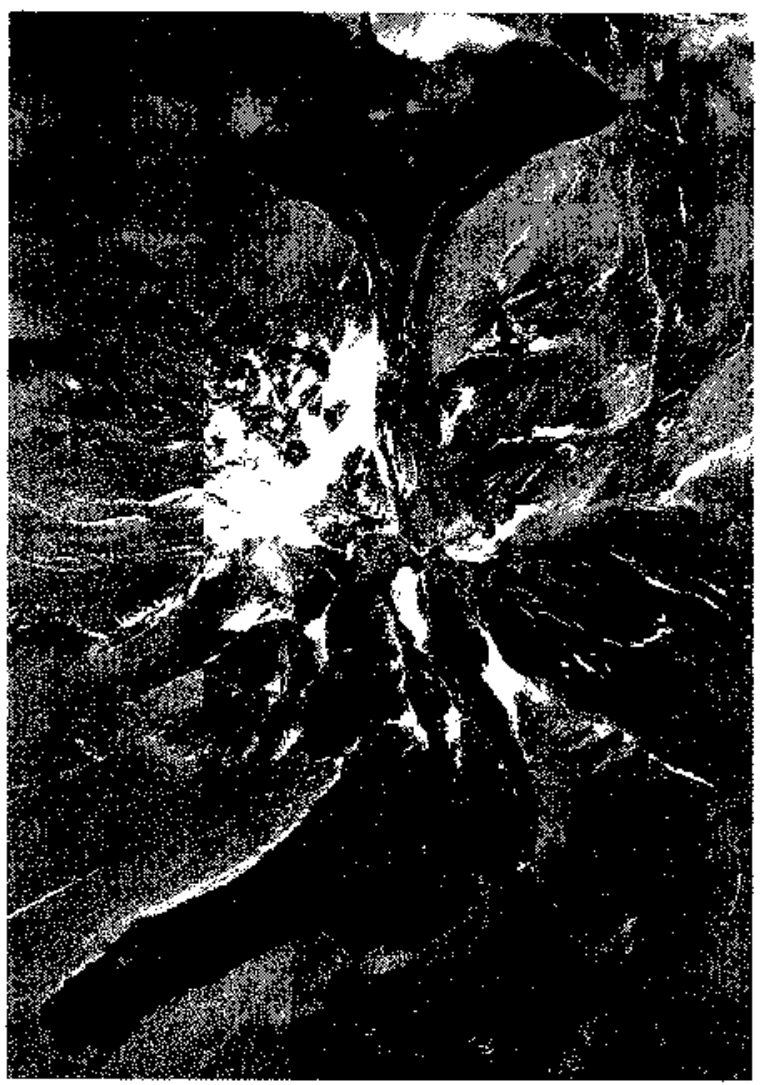

Figura 14. Mosaico de fotografías aéreas del Llullaillaco del 10 de abril de 1961 (El norte se orienta hacia la sectión superior de la hoja).

Figure 14. Aerial phofomosaic of Mt. Livilailiaco from April 10, 1961 (northuard up)

fluvial. Sólo las corrientes de lava Llullaillaco-II constituyen una excepción. Incluso las volcanitas Llullaillaco-I en parte presentan talwege incipientes en depresiones. También es llamativo que sólo a partir de los 5.300 a $5.500 \mathrm{~m}$ de altitud se observan formas solifluidales con sus lóbulos transversales, pero sin predominar sobre las estructuras fluviales.

La forma fluvial desarrollada a mayor altitud, es el surco de erosión. Los surcos comienzan en el borde de la meseta a $6.000 \mathrm{~m}$ de altitud, y cortan las terrazas solifluidales lavadas, con una pendiente que varía entre $20^{\circ}$ y $45^{\circ}$, aproximadamente. Las partes superiores de sus cursos son predominante- 
mente paralelos. Sólo en la parte media e inferior de la vertiente convergen los surcos - como consecuencia del meso-relieve-, y entre los 5.200 y 5.000 $m$, se transforman en talwege y valles. Los surcos de erosión son los cursos de deshielo recientes que pueden ser activados esporádicamente, siendo la intensidad formadora de los procesos más grande que la de las terrazas solifluidales lavadas.

Otra forma fluvial es el nicho de lavido. Los nichos de lavado existen en escombros de vertiente muy sueltos por debajo de los $5.000 \mathrm{~m}$ de altitud. En contraste con los surcos de erosión, los nichos constituyen un fenómeno de erosión planar, con una forma de vertiente cóncavo-convergente, en la cual pueden darse surcos de erosión lineal-concéntricos. Debido a los escombros de vertiente sueltos, se produce una regresión denudativa a gravitatoria de la vertiente, pudiéndose excluir en gran medida una influencia de la nivación debido a la altitud.

Una forma excepcional de la erosión fluvial de vertiente, se presenta en el lado argentino a los $6.100 \mathrm{~m}$ de altitud en una exposición ENE. En un horizonte de manantial, tienen su origen 18 surcos de erosión marcados y un gran número de surcos más pequeños. La configuración indica que se trata de una formación de relieve iniciada litoestructuralmente. Probablemente se produce el afloramiento de aguas recalentadas geotérmicamente. No se pudo clarificar definitivamente hasta qué punto existe una actividad reciente. Durante una inspección del terreno en marzo de 1996, no salía agua.

Entre las formas de acumulación fluvial, los conos de deyección son un fenómeno que se produce con la reducción abrupta de la pendiente. En muchos casos se presentan donde los talwege o valles secundarios pasan a valles principales con fondos más anchos y planos. Debido a la disminución repentina de la pendiente, se reduce la velocidad del flujo y se acumulan, por lo tanto, sedimentos fluviales.

En los talwege y valles mismos, se conservan terrazas fluviales cortadas por la acción fluvial en reiteradas ocasiones. Son un indicio destacado de procesos fluviales muy fuertes, posiblemente a muy corto plazo. Quedan pendientes investigaciones más detalladas acerca de las terrazas.

La última forma de acumulación fluvial es la planicie aluvial arenosa. En la zona de estudio existen dos planicies aluviales arenosas mayores: una, en el lado chileno al norte de la Quebrada La Barda a unos $4.530-4.550 \mathrm{~m}$ de altitud, y otra, en el lado argentino al sudeste del Portezuelo Llullaillaco Norte a los 4.685-4.700 $\mathrm{m}$ de altitud. Ambas planicies aluviales arenosas reciben recientemente alimentaciones de material muy pequeñas o nulas, de manera que han podido formarse suelos poligonales en su mayor parte grandes. En las planicies aluviales arenosas más pequeñas, las condiciones son parecidas. 


\subsubsection{Movimientos en masa}

En contraste con las formaciones de relieve autóctonas, en el caso de los movimientos en masa la parte claramente predominante del material es la removida. El fenómeno más marcado es la corriente de barro. Se habla de una corriente de escombros en blogues cuando el material predominantemente transportado es grueso. Los movimientos en masa repentinos que ocurren, se deben eventualmente a procesos endógenos; de todos modos el material es transportado en forma de una mezcla de agua, escombros y barro. La forma producida en e] área de origen de las masas desplazadas, es el nicho de despegue de escombros. Sólo formaciones jóvenes se clasificaron como corrientes de barro y corrientes de escombros en bloques. Cuando la forma ya ha sido retocada por procesos periglaciales, este proceso o su resultado fue cartografiado. De esto se desprende que no todos los nichos de despegue de escombros corresponden a una corriente de barro como forma de acumulación.

Otras dos formas de movimientos en masa, son los conos de escombros en bloques de formación casi exclusivamente gravitativa, $y$ los conos de escombros en sentido estricto, de material más fino. En el último caso, la gravitación es el proceso predominante, pero el transporte fluvial es claramente un proceso formador.

\subsubsection{Otras formas}

Como proceso importante hay que mencionar adicionalmente la bioturbación, que sólo está presente en el lado chileno entre los 4.200 y $4.400 \mathrm{~m}$ de altitud. En suelos poligonales de sustratos ordenados según la granulometría, los animales excavadores han producido y producen la remoción intensiva de material en los centros de polígono antes ricos en material fino, destruyendo de esta manera la forma inicial. Por lo tanto, estas superficies no se pueden interpretar como forma periglacial cuando se trata de las planicies particularmente afectadas. En el mismo piso altitudinal, las áreas de las vertientes están claramente formadas por el apresamiento por bloques.

El cráter constituye otra forma más, en el lado occidental de la meseta, que se encuentra a los $6.100 \mathrm{~m}$ de altitud y se extiende hasta los $6.020 \mathrm{~m}$. Sus flancos bastante inclinados están en su mayor parte cubiertos de campos de nieve, de modo que no se pudieron cartografiar las formas periglaciales. Las partes más bajas del crâter están cubiertas de hielo claro sin perturbaciones, lo que indica que aún recientemente se producen deshielos temporales debidos a la geotermia. En dos inspecciones - ambas realizadas a mediodía - no se observaron indicios de un derretimiento.

Bastante sorprendente resulta una última forma: los taffonis. Existe un gran número de ellos bastante grandes y profundos (Figura 15), entre los 


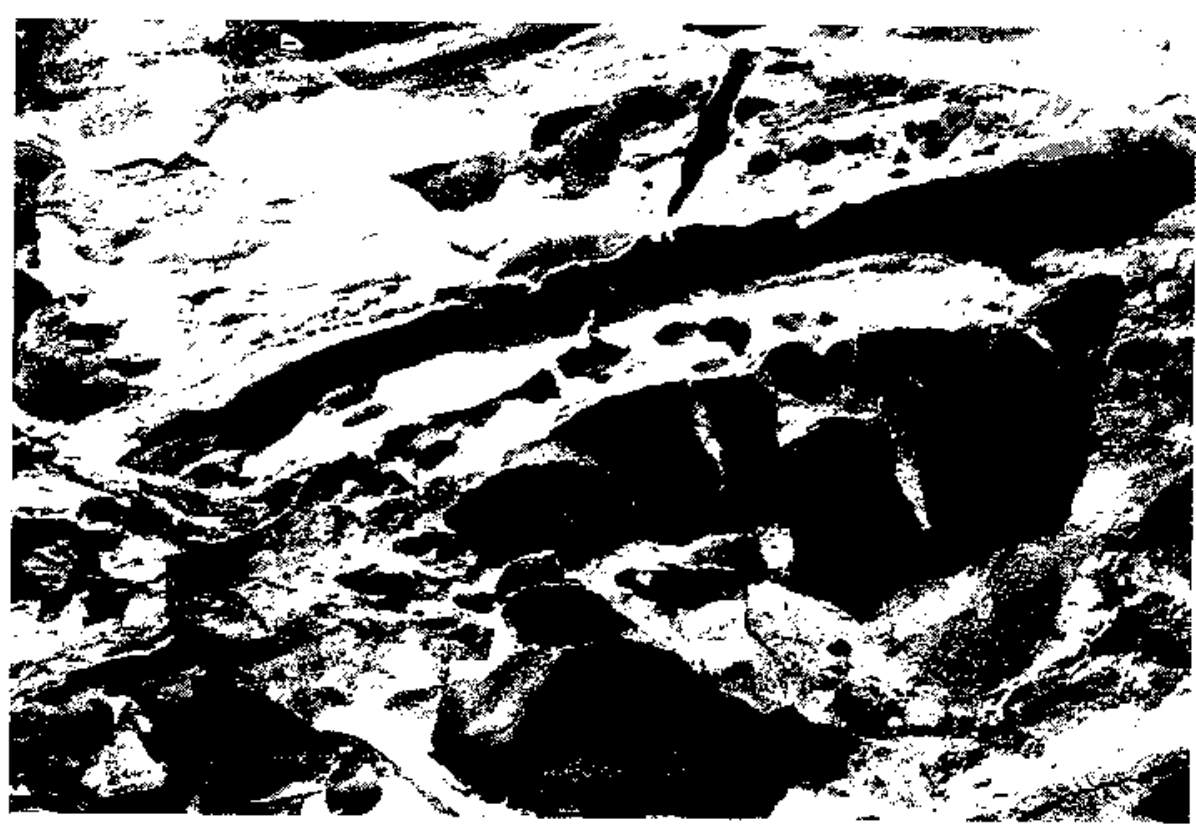

Figura 15. Bloque con Iaffoni a los $5.950 \mathrm{~m}$ de altitud. Figure 15. Taffoni-type weathering at $5,950 \mathrm{~m}$ a.s.l.

5.900 y $6.000 \mathrm{~m}$ de altitud en volcanitas pleistocenas en exposición norte y noroeste. Dado que los taffoni también fueron encontrados a unos $15 \mathrm{~km}$ de distancia del Llullaillaco a los $4.000 \mathrm{~m}$ de altitud y están ampliamente distribuidos en la costa chilena, parece tratarse de formas de meteorización del núcleo y de sombra, las cuales se presentan independientemente de la altitud.

\section{Los pisos altitudinales periglaciales del Llullaillaco}

Los climas subreciente y reciente deben considerarse responsables de la zonificación altitudinal periglacial.

A pesar de su gran importancia para los fenómenos periglaciales, sólo existen escasas informaciones acerca del clima subreciente. Las clasificaciones e indicaciones de PORTER (1981), HEINE (1985), MERCER (1985), MARKGRAF (1985), STINGL \& GARLEFF (1985), VILLEGRAN (1988), VILLEGRAN \& VARELA (1990) y GROSJEAN, MESSERLI \& SCHREIER (1991) se refieren a la fase altiglacial de la glaciación Würm y las fluctuacio- 
nes de humedad y temperatura postglaciales hasta 5000 A. P., aproximadamente. Para el Holoceno joven en el valle de Elqui (30'S), VEIT $(1991,1998)$ indica condiciones cálidas, semiáridas, temporalmente húmedas, con una baja de temperatura de 1 a $2 \mathrm{~K}$. El periodo entero se caracteriza por una leve aridizaciôn. Según GARLEFF et at. (1991), en el lado occidental de la Cordillera de los Andes a $30^{\circ} \mathrm{S}$, se insinúa una fase más húmeda a partir de 3000 A. P. Dado que esta zona se encuentra sometida a vientos del oeste ciclonales extratropicales, el máximo de la fase húmeda puede haber causado efectos dilatados en el Llullaillaco, a unos 5-6 de latitud más al norte.

En la Quebrada de las Zorritas a exactamente $4.000 \mathrm{~m}$ de altitud fue cartografiada y luego datada, una terraza arcillo-limosa con cintas delgadas de humus y depósitos de torrente intercalados (Figura 16). En su perfil se sacó un total de 20 muestras, de las cuales cuatro fueron datadas con el método de ${ }^{14} \mathrm{C} .{ }^{5}$ Las acumulaciones ocurrieron en un período entre $2436,8 \pm 49$ años A. $P$.

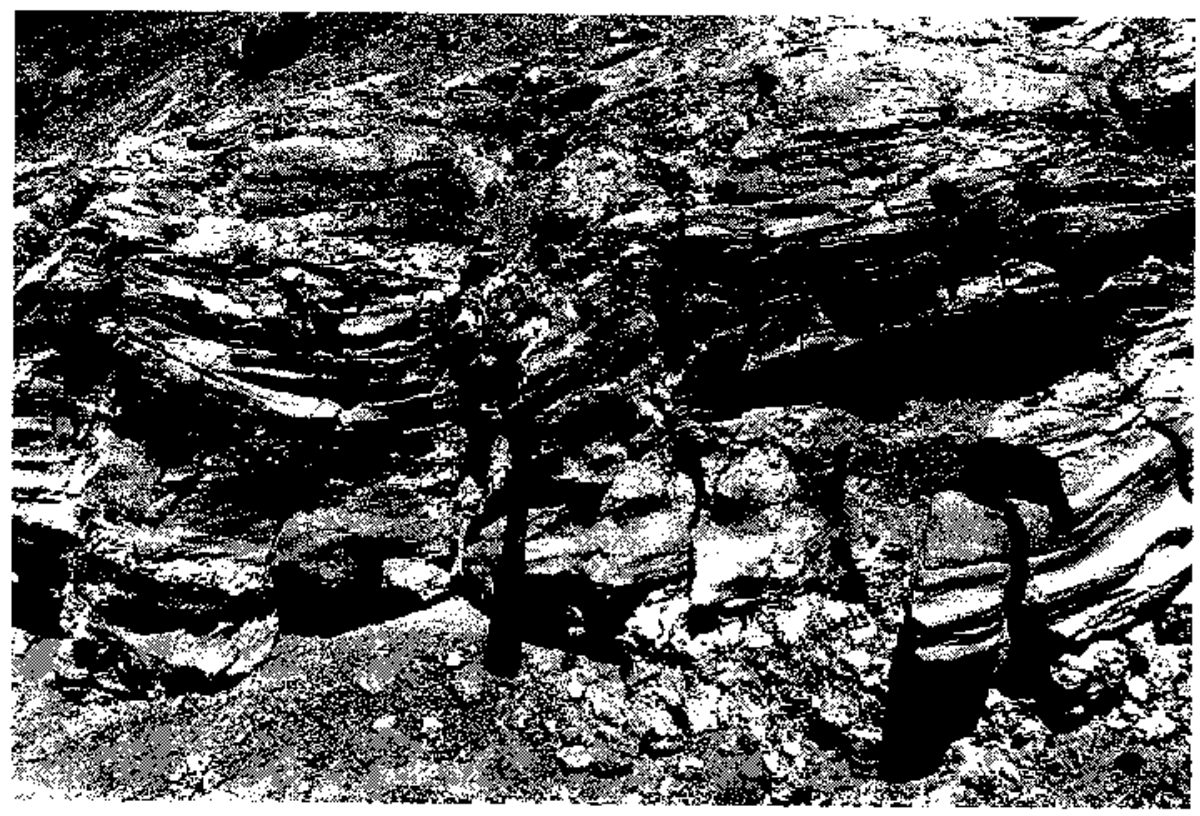

Figura 16. Limos lacustres en la Quebrada de las Zorritas a los $4.000 \mathrm{~m}$ de altitud.

Figure 16. Basin silt in the Quebrada de las Zorritas at 4,000 m a.s.l.

5 Se les agradece las dataciones "C al profesor KRETSCHMER y al señor MORGENROTH, de la cátedra de Física Experimental de la Unjversidad de Erlangen-N(ärnberg. 
y $1593,1 \pm 36$ años A.P. En un período de 850 años, aproximadamente, fueron depositadas 18 capas intercaladas de arcilla y humus. Las dataciones de las dos muestras que se encuentran aproximadamente en la mitad del ciclo de acumulación, indican que se trata de un ritmo bastante regular de acumulaciones de arcilla y humus (Figura 17). Dado que varios depósitos de torrente lenticulares están intercalados irregularmente, se puede stuponer que deben haber ocurrido varios desagizes intensos. Después de esta fase de desagües más fuertes y acumulaciones lacustres tranquilas, las condiciones climáticas convergieron con las actuales. Dado que en el presente la vegetación muestra coberturas muy bajas, carecen casi completamente de ella los derrubios de vertiente que actualmente se encuentran en la superficie (acumulación de los últimos 1500 arios). Por lo tanto, los errores en las dataciones ${ }^{14} \mathrm{C}$ debidos a raices más jóvenes deben ser insignificantes o nulos. Por ello, las dataciones ${ }^{14} \mathrm{C}$ en la zona central del desierto de Atacama se caracterizan, producto del clima, por una fiabilidad que no puede ser alcanzada en otras zonas de la Tierra. Habiendo usado además el error 2-sigma, las dataciones tienen una gran exactitud, según todo lo que sabemos.

Este período más húmedo juega un papel decisivo en el desarrollo de las formas periglaciales. Las temperaturas en el área del Llullaillaco son tan bajas que en el presente puede caer nieve hasta los $4.000 \mathrm{~m}$ de altitud, por lo cutal una mayor humedad y una eventual transición de precipitaciones esporádicas a periódicas significan que en ese tiempo se podían formar regularmente cubiertas de nieve. La mayor humedad bajo temperaturas constantes o parecidas debe haber estimulado los procesos formadores periglaciales y aumentado la denudación de vertiente. Sólo de esta manera se puede explicar el hecho de que se observen suelos de sustrato ordenado hasta una altitud de $3.900 \mathrm{~m}$, a pesar de que hasta $\operatorname{los} 4.300 \mathrm{~m}$ no existen formas recientes en las planicies. Este piso inferior, cuyo límite superior en el Llullaillaco se encuentra a los $4.300 \mathrm{~m}$ de altitud, fue denominado por VEIT (1991) a los

\begin{tabular}{|lccc|}
\hline Muestra & Edad A.P. & Edad de calendario calibrada, error 2- $\sigma$ & pronedio, error 2- $\sigma$ \\
\hline tn-1 & $1593,1 \pm 36$ & $412-550$ & $481 \pm 69$ \\
tn-9 & $2097,9 \pm 42$ & $194-0$ & $97 \pm 97$ \\
tn-11 & $2214,4 \pm 42$ & $382-176$ & $275 \pm 103$ \\
tn-18 & $2436,8 \pm 49$ & $762-400$ & $581 \pm 181$
\end{tabular}

Figura 17. Dataciones ${ }^{19} \mathrm{C}$ de sedimentos arcillo-limosos de una terraza a los $4.000 \mathrm{~m}$ de altitud en la Quebrada de las Zorritas.

Figure 17. Radiocorbon age determination of a clay-sitt terrace sediment in the Quebrado de las Zorritis at $4,000 \mathrm{~m}$ a.s.t. 
$30^{\circ} \mathrm{S}$, piso de movimientos de material de poca profundidad (Piso Altitudinal Subandino). Su límite superior se encontró a los $3.500 \mathrm{~m}$. En el Llullaillaco, se debe tratar de un piso en reposo de formación periglacial casi completo en las planicies, producto de la mayor aridez. En vertientes de fuerte pendiente, sin embargo, se observan bloques-presa hacia abajo hasta los $4.100 \mathrm{~m}$ de altitud, cuyo cubrimiento fue iniciado en el tiempo subreciente y fue retocado predominantemente por procesos gravitativos. La combinación de estos procesos con la acción permanente de procesos eólicos y en parte el lavado esporádico, produjo en total la denudación de las vertientes en las terrazas de al menos 1500 años de edad, de manera que el área entre los 4.100 y 4.300 m puede ser denominada zona de criodenudación. A partir de los $4.300 \mathrm{~m}$, se presentan más ampliamente las formas pequeñas de la formación de suelos estructurados. Además de las franjas de piedras y polígonos débiles, se puede observar el engranaje de bloques-presa y crioplanación. No sólo los ejes en profundidad de las fracciones gruesas sobre las superficies planas están orientados verticalmente, sino que esto también se observa en el área de los bloques cubiertos. Este área denominada como ya dijimos Piso Altitudinal Andino por VEIT (1991), termina en el Llullaillaco a los $4.700 \mathrm{~m}$ en el lado chileno, y a los $4.950 \mathrm{~m}$, aproximadamente, en el lado argentino más árido (Figura 18).

Más arriba sigue el Piso Periglacial propiamente dicho. Ahí dominan la solifluxión, la formación de suelos estructurados y de vertientes rectilíneas. En la parte inferior aún se observa un gran número de bloques-presa. La zona de formación óptima de bloques-presa coincide aproximadamente con el límite superior del piso andino. A continuación están los movimientos solifluidales que modelan la superficie cada vez más. El piso de formación óptima de éstos se encuentra entre los 5.100 y $5.400 \mathrm{~m}$ en el lado chileno y entre los 5.350 y $5.700 \mathrm{~m}$ en el lado argentino, alcanzándose altos de frente de hasta $1 \mathrm{~m}$. Hacia arriba, los alıos de los lóbulos de solifluxión disminuyen de manera relativamente rápida. Esto supuestamente se debe sobre todo al hecho de que el permafrost continuo obstaculiza movimientos más intensivos. En marzo el f́rente de helada se enconctró a $50 \mathrm{~cm}$ de profundidad a los $5.400 \mathrm{~m}$ de altitud, y a $30 \mathrm{~cm}$ a $\operatorname{los} 5.850 \mathrm{~m}$. Comparando las mediciones climáticas en el Liullaillaco con las del Sairécabur (SCHMIDT, 1993 y 1995). las temperaturas máximas diarias del suelo a 5 y $10 \mathrm{~cm}$ de profundidad son $2 \mathrm{~K}$ a $3 \mathrm{~K}$ más bajas en las mediciones de invierno tardío que en verano tardío, pero a $20 \mathrm{~cm}$ de profundidad sólo $1 \mathrm{~K}$ más bajas. Entre los 30 y $40 \mathrm{~cm}$ de profundidad, las temperaturas deberian haberse igualado. Esto tiene como consecuencia que el frente del permafrost en el Llullaillaco y Sairécabur se encuentra aproximadamente en la misma profundidad. SCHMIDT (com. oral) supone que el frente del permafrost está a $50 \mathrm{~cm}$ a los 
PIRINEOS 155

\begin{tabular}{|c|c|c|}
\hline Altitud ( $m$ s.n.m) & Piso nllitudinal reciente & $\begin{array}{l}\text { Procesos y formas geomorfologicos } \\
\text { recientes }\end{array}$ \\
\hline $6.300-6.739$ & Piso Periglacial Superior & $\begin{array}{l}\text { Superficies de gelifracción in situ } \\
\text { con procesos desconocidos }\end{array}$ \\
\hline $5.800-6.300$ & Pișo Periglacial Medio & $\begin{array}{l}\text { movimientos de material de poca } \\
\text { profundidad con predominio de } \\
\text { lavado en superficies de gelifrac- } \\
\text { ción y terrazas de solifluxión; peni- } \\
\text { tentes de nieve y nevé quebrado } \\
\text { aislados }\end{array}$ \\
\hline $4.700-5.800$ & Piso Periglacial Inferior & $\begin{array}{l}\text { movimientos de material profundos } \\
\text { (hasta el frente del permafrost), pre- } \\
\text { dominan solifluxión, formación de } \\
\text { vertientes rectilineas y de suelos } \\
\text { estructurados }\end{array}$ \\
\hline $4.300-4.700$ & Piso Andino & $\begin{array}{l}\text { movimientos de material de poca } \\
\text { profundidad con formas periglacia- } \\
\text { les incipientes y predominio de } \\
\text { apresamiento por bloques; criopla- } \\
\text { nación }\end{array}$ \\
\hline $4.100-4.300$ & Piso Subandino/Andino & $\begin{array}{l}\text { en las vertientes, movimientos de } \\
\text { material débiles debidos a las hela- } \\
\text { das; criodenudación en superficies } \\
\text { planas }\end{array}$ \\
\hline menos de 4.100 & Piso Subandino & $\begin{array}{l}\text { ausencia de movimientos de mate- } \\
\text { rial debidos a las heladas }\end{array}$ \\
\hline
\end{tabular}

Figura 18. Zonificación altitudinal reciente del Llullaillaco en el lado noroccidental chileno. Figure 18. Present altitudinal zonation of Mt. Llullaillaco on the north-western Chilean side.

$5.500 \mathrm{~m}$ de altitud en el Sairécabur. A los $5.850 \mathrm{~m}$, las diferencias deberían haber desaparecido.

En la parte baja del piso periglacial raras veces se observan fenómenos de lavado. Luego a partir de los $5.800 \mathrm{~m}$ se observa que los surcos de erosión modelan los lóbullos de solifluxión en mayor medida. En contraste a VEIT (1991), quien pudo observar fenómenos de lavado en el piso periglacial entero, se distinguió entre los Pisos Periglacial Inferior con poco a nulo lavado, y Periglacial Medio caracterizado predominantemente por el lavado. Hacia mayores altitudes, las formas de meteorización in situ se van extendiendo. Las superficies de gelifracción lavadas predominan. El levantamiento cartográfico sólo pudo ser efectuado hasta los $6.300 \mathrm{~m}$ por razones meteorológicas. 
Las formas de lavado ya empiezan a suspenderse a esta altitud, y las superficies de gelifracción definen la morfología en exclusiva. Queda pendiente hasta qué punto existe una asociación con otros procesos formadores en el Piso Periglacial Superior.

En futuras investigaciones se van a examinar la variabilidad del periglacial y la extensión del permafrost.

\section{Conclusiones}

Fruto de los trabajos llevados a cabo en el volcán Llullaillaco, ahora conocemos el patrón de distribución de las formas periglaciares y la zonificación geomorfológica altitudinal del área más árida y más alta del eje de máxima aridez del desierto de Atacama. Durante el Pleistoceno no se registraron glaciaciones. Además, el clima presentó un periodo más húmedo entre los años 2.500 y 1.500 A. P.

\section{Referencias}

ACEITUNO, P. (1989). On the functioning of the southern oscillation in the South American sector. Part II: Upper-air circulation. Joumal of Climate, 2: 341-355.

ARAVENA, R.; PENA, H.; GRILLI, A.; SUZUKI, O. \& MORDECKAI, M. (1989). Evolución isotópica de las lluvias y origen de las masas de aire en el Altiplano chileno. En: Isotope Hydrology Investigations in Latin America. Toronto, 129-142. = IAEA-TECDOC, 502.

BRETTSCHNEIDER, H. (1980). Mikroklima und Verwitterung an Beispielen aus der Sierra Nevada Spaniens und aus Nordafrika mit Grundlagenstudien zur Glatthanggenese. En: HEMPEL, L. \& H. BRETTSCHNEIDER [Ed.]: Beiträge zur «Energetischen Geomorphologie» in Trockengebieten. Paderborn, 65-141. Münstersche Geogr. Arb., 9.

BRYAN, K. (1946). Cryopedology. The study of frozen ground and intensive frost-action with suggestions on nomenclature. Amer. Journal Sci., 244: 622-642.

BÜDEL, J. (1977). Klima-Geomorphologie. Berlin, Stuttgart.

DEMEK, J. (1968). Cryoplanation terraces in Yakutia. Bitl. Peryglacjalny, 17: 91-116. 
ENDLICHER, W. (1983). Zur Witterungsklimatologie der WinterregenSubtropen Chiles. Erdkunde, 37: 258-268.

GARDEWEG, M., RAMIIREZ, C. F. \& DAVIDSON, J. (1993). Mapa Geológico del Área del Salar de Punta Negra y del Volcán Llullaillaco. Santiago de Chile. = Seroicio Nac. Geol. y Minería, 5.

GARLEFF, K, SCHÄBITZ, F, STINGL, H. \& VEIT, H. (1991). Jungquartäre Landschaftsentwicklung und Klimageschichte beiderseits der Ariden Diagonale Südamerikas. Bamberger Geogr. Schriften, 11: 359-394.

GROSJEAN, M., MESSERLI, B. \& SCHREIER, H. (1991). Seenhochstände, Bodenbildung und Vergletscherung im Altiplano Nordchiles: Ein interdisziplinärer Beitrag zur Klimageschichte der Atacama. Erste Resultate. Bamberger Geogr. Schriften, 11: 55-108.

HAGEDORN, J. (1970). Zum Problem der Glatthänge. Z. Geomorph, 14 (1): 103-113.

HEINE, K. (1985). Jungquartäre Klimaschwankungen auf der Südhalbkugel. Zbl. Geol. Paläont, Teil $\mathrm{l}$, (11/12): 1751-1768.

HOFFMANN, J. A. J. (1992). Das kontinentale Luftdruck- und Niederschlagsregime Südamerikas. Erdkunde, 46: 40-51.

KARRASCH, H. (1972). Flächenbildung unter periglazialen Klimabedingungen? Göttinger Geogr. Abh., 60: 155-168.

KELLETAT, D. \& GASSERT, D. (1975). Die Formengruppe Pediment Glatthang - Felsfächer der westlichen Mani-Halbinsel, Peloponnes. Die Erde, 106 (3): 174-192.

KNEISEL, C. et al. (1998). Legende für geomorphologische Kartierungen in Hochgebirgen (GMK Hochgebirge). Trierer Geogr. Studien, H. 5.

KUGLER, H. (1974). Das Georelief und seine kartographische Modellierung. Diss. B. Halle (Saale).

LAUER, W. (1988). Zum Wandel der Vegetationszonierung in den Lateinamerikanischen Tropen seit dem Höhepunkt der letzten Eiszeit. $J b$. Geogr. Ges. Hannover, 1-45.

LAUER, W. \& ERLENBACH, W. (1986). Die tropischen Anden. Geoökologische Raumgliederung und ihre Bedeutung für den Menschen. Geogr. Rundschau, 39: 86-97.

LEHMKUHL, F. (1991/92). Breitböden als glaziale Erosionsformen - ein Bericht über Vergletscherungstypen im Qilin Shan und Kunlun Shan (China). Z. Gletscherkunde u. Glaziologie, 27/28: 51-62.

LOUIS, H. \& FISCHER, K. (1979). Allgemeine Geomorphologie. Berlin, New York.

MARKGRAF, V. (1985). Palaeoenvironmental history of the last 10,000 years in northwestern Argentina. Zbl. Geol. Paläont., Teil I, (11/12): 1739-1749. 
MERCER, J. H. (1985). Changes in the ice cover of temperate and tropical South America during the last 25,000 years. Zbl. Geol. Paliont., Teil I, (11/12): 1661-1665.

PORTER, S. (1981). Pleistocene glaciation in the Southern Lake District of Chile. Quat. Res., 16: 263-292.

RICHTER, M. (1995). Klimaökologie Atacama. DFG Abschlußbericht, Ri 370/1$4 \& 2-4$. Erlangen.

RICHTER, M. (1996). Klimatologische und pflanzenmorphologische Vertikalgradienten in Hochgebirgen. Erdktude, 50: 205-238.

RICHTER, M. \& SCHRÖDER, H. (1998). Remarks on the Paleoecology of the Atacama basing on the latest distribution patterns. Bamberger Geogr. Schriften, 15: 57-69.

SCHMIDT, D. (1993). Klimaökologie Atacama - Projektteil Klima. DFG-Bericht, Ri 370/1-4. Erlangen.

SCHMIDT, D. (1995). Klimaokologie Atacama - Projektteil Klima. DFGAbschlußbericht, Ri 370/1-4 \& 2-4. Erlangen.

SCHRÖDER, H. (1996). Periglazial des Llullaillaco. DFG-Bericht, Schr 379/4-2. Erlangen.

SCHRÖDER, H. \& BERKNER, A. (1986). Zur Geomorphologie des Rila- und Piringebirges (VR Bulgarien). Geogr. Ber., 31 (3): 145-158.

SCHRÖOER, H., MAKKI, M. \& CIUTURA, M. (1996). Die Zusammensetzung und morphologische Wirksamkeit der Salze in der ariden Höhenregion der Atacama (Chile). Mitt. d. Fränk. Geogr. Ges., 43: 259-273. Erlangen.

SCHRÖDER, H. \& M. MAKKI (1998). Das Periglazial des Llullaillaco. Peterm. Geogr. Mitt., 142/2: 67-84.

SCHROTT, L. (1994). Die Solarstrahlung als steuernder Faktor im Geosystem der subtropischen semiariden Hochanden (Agua Negra, San Juan, Argentinien). Heidelberg. Heidelberger Geogr. Arb., 94.

STINGL, H. \& GARLEFF, K. (1983). Beobachtungen zur Hang- und Wandentwicklung in der Periglazialstufe der subtropisch-semiariden Hochanden Argentiniens. Abh. Akad. Wiss. Göttingen, Math.-phys. Kl., $3 \mathrm{~F}$, 35: 199-213.

STINGL, H. \& GARLEFF, K. (1985). Spätglaziale und holozäne Gletscher- und Klimaschwankungen in den argentinischen Anden. Zbl. Geol. paläont., Teil I. (11/12): 1667-1677.

VEIT, H. (1991). Jungquartäre Relief- und Bodenentwicktung in der Hochkordillere im Einzugsgebiet des Río Elqui (Nordchile, $30^{\circ} \mathrm{S}$ ). Bamberger Geogr. Schriften, 11: 81-97. 
VEIT, H. (1998). Holocene climatic changes and atmospheric palaeocirculation in the northwestern part of the «Arid Diagonal» of South America. Bamberger Geogr. Schriften, 15: 355-369.

VILLEGRAN, C. (1988). Expansion of Magellanic Moorland during the Late Pleistocene: Palynological Evidence from Northern Isla de Chiloé, Chile. Quat. Res., 30: 304-314.

VILLEGRAN, C. \& VARELA, J. (1990). Palynological evidence for increased aridity in the central Chilean coast during the Holocene. Quat. Res., 32: 198-207.

VUILLE, M. (1996). Zur raumzeitlichen Dynamik von Schneefall und Ausaperung im Bereich des südlichen Altiplano, Südamerika. Bern. = Geographica Bernensia, G 45 .

WASHBURN, A. L. (1979). Geocryology. A survey of periglacial processes and environments. London.

WEISCHET, W. (1969). Zur Geomorphologie des Glatthang-Reliefs in der ariden Subtropenzone des Kleinen Nordens von Chile. Z. Geomorph, N. F, 13: 1-21.

WEISCHET, W. (1988). Die Niederschlagsbedingungen in Nordwestargentinien, speziell das Problem ihres vertikalen Wandels. $\mathrm{Jb}$. Geogr. Ges. Hannover, 47-64.

WEISE, O. R. (1983). Das Periglazial. Berlin, Stuttgart. 